\title{
Seed bubbles trigger boiling heat transfer in silicon microchannels
}

\author{
Guohua Liu $\cdot$ Jinliang Xu $\cdot$ Yongping Yang
}

Received: 18 March 2009/Accepted: 28 May 2009/Published online: 16 June 2009

(C) Springer-Verlag 2009

\begin{abstract}
The smooth channel surface of microsystems delays boiling incipience in heated microchannels. In this paper, we use seed bubbles to trigger boiling heat transfer and control thermal non-equilibrium of liquid and vapor phases in parallel microchannels. The test section consisted of a top glass cover and a silicon substrate. Microheater array was integrated at the top glass cover surface and driven by a pulse voltage signal to generate seed bubbles in time sequence. Each microheater corresponds to a specific microchannel and is located in the microchannel upstream. Five triangular microchannels with a hydraulic diameter of $100 \mu \mathrm{m}$ and a length of $12.0 \mathrm{~mm}$ were etched in the silicon substrate. A thin platinum film was deposited at the back surface of silicon chip with an effective heating area of $4,500 \times 1,366 \mu \mathrm{m}$, acting as the main heater for the heat transfer system. Acetone liquid was used. With the data range reported here, boiling incipience was not initiated if wall superheats are smaller than $15^{\circ} \mathrm{C}$ without seed bubbles assisted. Injection seed bubbles triggers boiling incipience and controls thermal non-equilibrium between liquid and vapor phases successfully. Four modes of flow and heat transfer are identified. Modes 1, 2, and 4 are the stable ones without apparent oscillations of pressure drops and heating
\end{abstract}

G. Liu · J. Xu $(\bowtie)$

Micro Energy System Laboratory,

Guangzhou Institute of Energy Conversion,

Chinese Academy of Science, 510640 Guangzhou,

People's Republic of China

e-mail: xuj1@ms.giec.ac.cn

Y. Yang $(\bowtie)$

Beijing Key Laboratory of Energy Safety and Clean Utilization,

North China Electric Power University, 102206 Beijing,

People's Republic of China

e-mail: yyp@ncepu.edu.cn surface temperatures, and mode 3 displays flow instabilities with apparent amplitudes and long periods of these parameters. The four modes are divided based on the four types of flow patterns observed in microchannels. Seed bubble frequency is a key factor to influence the heat transfer. The higher the seed bubble frequency, the more decreased non-equilibrium between two phases and heating surface temperatures are. The seed bubble frequency can reach a saturation value, at which heat transfer enhancement attains the maximum degree, inferring that a complete thermal equilibrium of two phases is approached. The saturation frequency is about a couple of thousand Hertz in this study.

Keywords Seed bubble - Microchannel .

Boiling incipience . Thermal non-equilibrium

\section{Introduction}

Microsystems with boiling heat transfer inside have received great attention because they involve many engineering applications. Applications include electronic cooling at high heat flux (Thome 2004), thermal control of fuel cells (Garrity et al. 2007), microthruster force generation for micro/nano satellites (Maurya et al. 2005), etc. Channel surface of MEMS (microelectromechanicalsystems) is very smooth by the microfabrication technique. For instance, Lin (1998) scanned a polysilicon microheater surface and found that the roughness was $6.5 \mathrm{~nm}$ by atomic force microscope (AFM), which is the same size as a critical bubble size. Bubble nucleation in smooth silicon microstructures is either a homogeneous one, or a heterogeneous one on the surface with micro/nano cavities. Wall superheat at the onset of nucleation boiling (ONB) is significantly high. Kandlikar et al. (1997) numerically modeled the flow over a 
bubble attached to a channel wall at a given contact angle and gave a bubble nucleation criterion. Wall superheats were given against the cavity sizes in micron scale. The nucleation criterion represents the lowest temperature at which a cavity of a given size will nucleate. These cavities will continue to nucleate at higher superheats as seen in their plotting curves. If cavities of this radius are not available, onset of nucleation will be delayed into the downstream part of the channel until the wall superheat meets the bubble nucleation criterion. If the onset of nucleation occurs over cavities of radius $3 \mu \mathrm{m}$, the minimum wall superheat required to initiate in the channel should be $15^{\circ} \mathrm{C}$ with saturated water in a $1,054 \times 197 \mu \mathrm{m}$ channel, mass flux of $120 \mathrm{~kg} /\left(\mathrm{m}^{2} \mathrm{~s}\right)$, and heat flux of $300 \mathrm{~kW} / \mathrm{m}^{2}$. Kandlikar (2002) summarized fundamental issues related to flow boiling in microchannels. Liu et al. (2005) investigated the onset of nucleate boiling (ONB) in the flow of water through a microchannel heat sink. The microchannels considered were $275 \mu \mathrm{m}$ wide by $636 \mu \mathrm{m}$ deep. An analytical model was developed to predict the incipient heat flux as well as the bubble size at the onset of boiling. The closed-form solution obtained sheds light on the impact of the important system parameters on the incipient heat flux. Kandlikar (2006) stated that wall superheats at the ONB are in general quite high in microchannels, even in the presence of right sized cavities. Introduction of artificial cavities on channel wall surfaces alone may not be enough to suppress flow instabilities due to the rapid bubble growth. Thus, they proposed the hybrid technique of pressure drop elements and fabricated nucleation sites to suppress flow instabilities in microchannels. Yu et al. (2006) performed pool boiling heat transfer experiments using artificial microcavity surface immersed in FC-72 liquid. Even though microcavities were used, wall superheats could reach several tens of degrees at the boiling incipience. Pool boiling heat transfer experiments of water with uniform size cavities on the wall surface was performed by Sato et al. (2008). Cylindrical holes of $10 \mu \mathrm{m}$ in diameter and $40 \mu \mathrm{m}$ in depth were formed on a mirror-finished silicon wafer of $0.525 \mathrm{~mm}$ in thickness using microfabrication technology. They found that when the spacing between cavities was small, strong thermal and bubble coalescence interactions between nucleation sites were observed, leading to strong convection accounted for a large part of the heat transfer. As the cavity interval became wide, the thermal and bubble coalescence interactions between nucleation sites became quite low, to the extent of being negligible. Thus, they concluded that the cavity spacing is an important parameter to influence the enhanced heat transfer under pool boiling conditions.

Wettable channel surface also causes high wall superheats at the boiling incipience, affecting the system start-up and shortening the system life span. Flow instabilities in microchannels are highly related to high boiling incipience temperature. Liquid should be highly superheated to initiate boiling heat transfer, leading to the rapid bubble growth (Hetsroni et al. 2005). The produced vapor by the rapid bubble growth occupies the whole channel cross section and the flow rate should be reduced. The external applied pressure pushes vapor out of microchannels when the superheated liquid completely releases its energy to vapor, leading to refilling of the incoming subcooled liquid. There is a waiting time for liquid to reach a high superheat to trigger the boiling heat transfer again. The above process is repeated in time sequence and the alternating liquid/twophase flow, or the liquid/two-phase/vapor flow, is sustained in heated microchannels, as reported by many investigators such as Wu and Cheng (2003), Chang and Pan (2007), Huh et al. (2007), etc.

$\mathrm{Xu}$ et al. (2009) deals with flow instabilities in microchannels. They use seed bubbles to stabilize flow and heat transfer in microchannels. Boiling numbers are larger than those reported in the present paper. Thus, the oscillating boiling heat transfer is sustained in microchannels without seed bubbles assisted. Seed bubbles at low frequencies shorten the oscillating cycle periods and decrease the oscillating amplitudes of pressure drops and heating surface temperatures.

In this study, we deal with boiling incipience in microchannels. We use seed bubbles to eliminate temperature excursions. The idea happens to be covered in a patent of Thome and Dupont (2007). The heat transfer assembly in Thome and Dupont (2007) consists of an evaporator and a bubble generator connected by a tube. In this paper, seed bubble generators are within microchannels and driven by a pulse voltage signal. Each microheater corresponds to a specific microchannel and is located in the microchannel upstream. In order to eliminate temperature excursions, wall superheats are smaller than $15^{\circ} \mathrm{C}$, thus superheated liquid flow exists in microchannels without bubble nucleation. Injection seed bubbles successfully triggers boiling incipience and controls thermal non-equilibrium between liquid and vapor phases, involving four modes of flow and heat transfer. Modes 1 and 2 involve stable heat transfer, referring to either the alternating liquid and elongated bubble flow with the switch frequency identical to that of the pulse voltage signal for mode 1 , or the seed bubble train flow in microchannels for mode 2 . Mode 3 behaves flow instabilities with apparent oscillating amplitudes and long periods of pressure drops and heating surface temperatures. Alternating bubble flow and elongated bubble flow appear in microchannels, with low switch frequency that is different from that of the pulse voltage signal. Mode 4 takes place at high boiling numbers and behaves stable pressure drops and heating surface temperatures but self-boiling does not happen. Quasi-stable seed bubbles and elongated bubbles coexist in microchannels at any time. 


\section{Experiment}

2.1 Description of the seed bubble guided heat transfer system (Xu et al. 2009)

The heat transfer system is shown in Fig. 1, consisting of a top 7740 glass cover (Fig. 1a) and a bottom silicon substrate (Fig. 1b). It had a length of $22.6 \mathrm{~mm}$. The glass cover had a width of $9.0 \mathrm{~mm}$, which was wider than the silicon substrate by $3.0 \mathrm{~mm}$, leaving two $1.5 \mathrm{~mm}$ margins in the width direction to ensure the signal wire bonding for seed bubble generators. Thicknesses of glass cover and silicon substrate were 525 and $400 \mu \mathrm{m}$, respectively. At the back surface of the glass cover, five platinum film microheaters were connected consecutively by gold film layer, acting as the seed bubble generator array (see the red and black area in Fig. 1a). Each platinum film microheater had a size of $50 \mu \mathrm{m} \times 20 \mu \mathrm{m}$. Microheaters are located within microchannels. The distance between the microheater array and the microchannel entrance was $500 \mu \mathrm{m}$ along the flow direction (see Fig. 1c).

Two conical cavities were etched and followed by two circular holes in the silicon substrate, acting as the inlet and outlet fluid pools. The two circular holes with a diameter of
Fig. 1 Seed bubble guided heat transfer system, all dimensions are in $\mu \mathrm{m}, 1$ and 3 are the resistances of gold pads ( $R_{\mathrm{au} 1}$ and $\left.R_{\mathrm{au} 2}\right), 2$ is the resistance of the five microhetaers $\left(R_{\mathrm{fi}}\right), 4$ is the bonding channel with the depth of $1.5 \mu \mathrm{m}$ to suspend the gold pad, 5 is the signal wire for the seed bubble generations, the red rectangular area in Fig. $1 \mathrm{~b}$ is the effective heating area at the back surface of the silicon substrate (main heater)
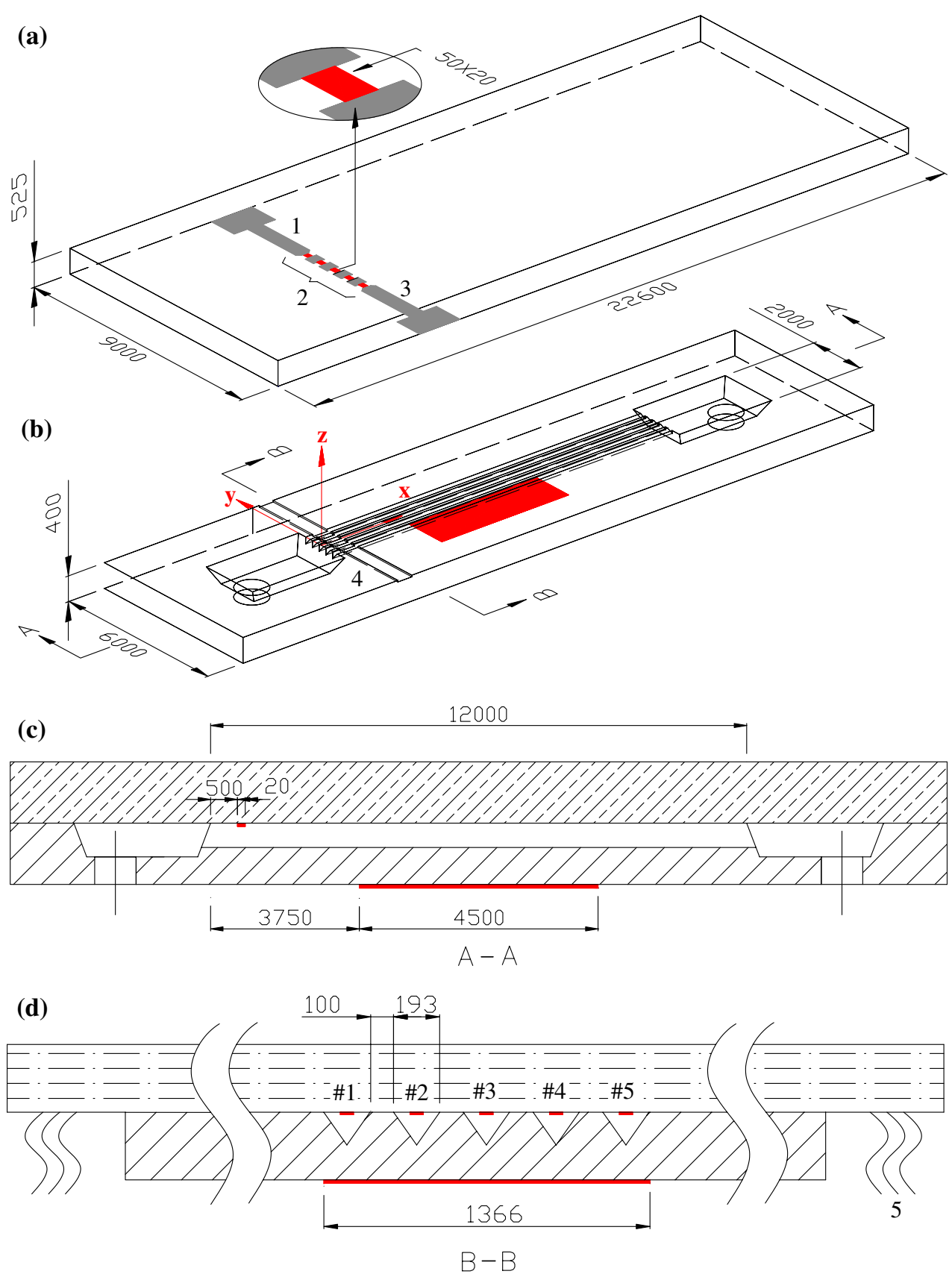
$1.0 \mathrm{~mm}$ were connected with capillary tubes for the fluid supply. Each triangular microchannel had a hydraulic diameter of $100 \mu \mathrm{m}$ with a width of $193.2 \mu \mathrm{m}$ and a depth of $136.6 \mu \mathrm{m}$. The five microchannels had a total width of $1,366 \mu \mathrm{m}$ with a distance of $100 \mu \mathrm{m}$ between two neighboring channels. The microchannels had a length of $12,000 \mu \mathrm{m}$. A bonding channel with a depth of $1.5 \mu \mathrm{m}$ was etched on the top surface of the silicon substrate to suspend the gold conductor layer. The microsystem packaging includes seal of the bonding channel by thermal glue to prevent liquid leakage.

A main heater was deposited at the back surface of the silicon substrate with a length of $4,500 \mu \mathrm{m}$ and a width of $1,366 \mu \mathrm{m}$. The heater was made by platinum, acting as the heating source for the micro heat transfer system. Cross sections of A-A and B-B referring to Fig. 1b are shown in Fig. 1c, d. Five microchannels were numbered as \#1-5 in Fig. 1d.

Coordinates of $x, y$, and $z$ are set as the axial flow direction, chip width direction, and chip thickness direction, respectively (see Fig. 1b). Coordinates of $(0,0,0)$ are at the microchannel entrance in axial direction, chip centerline in width direction and top surface of the silicon substrate. The flow was from left to right, referring to Fig. 1. This coordinate system is for the flow pattern characterization. In order to evaluate the heat transfer performance at the back surface of silicon chip $(4,500 \times$ $1,366 \mu \mathrm{m})$, another two-dimensional attached coordinate system $\left(x_{\text {film }}, y_{\text {film }}\right)$ was set, with $x_{\text {film }}=0$ at the beginning of the effective heating area, and $y_{\text {film }}=0$ at the centerline of the main heating area.

\subsection{The microsystem fabrication}

Figure 2 shows the microsystem fabrication procedure. Initially a 4-in., double polished silicon wafer was rinsed. Fabrication of the silicon wafer involves following steps: (a) double side thermal oxidation layers deposited on the silicon wafer to $3,000 \AA$, (b) double side silicon nitride layers deposited to $1,500 \AA$ by the low pressure chemical vapor deposition (LPCVD) technique, (c) a photoresist layer spun at the back surface of the silicon wafer, and the lithographic processing applied, (d) back side titanium film deposition to $1,000 \AA$ and platinum film deposition to $1,500 \AA$, (e) back side photoresist layer removed and exposing the platinum film, (f) photoresist layer spun on the top side of the silicon wafer, $(\mathrm{g})$ back side oxidation and nitride layers etching, (h) inlet and outlet fluid pools etching by $\mathrm{KOH}$ solution, (i) removal of the photoresist layer on the top side of silicon wafer, etching of the top side nitride layer, (j) lithographic process applied on the bonding channel with a depth of $1.5 \mu \mathrm{m}$, $(\mathrm{k})$ etching of the oxidation layer on the bonding channel surface, (l) removal of the photoresist layer, $(\mathrm{m})$ photoresist layer spun on the top side of silicon wafer and lithographic process applied, (n) selective etching of the oxidation layer to $3,000 \AA$, (o) wet etching of the triangular channel to a depth of $136.6 \mu \mathrm{m}$ by $\mathrm{KOH}$, (p) wet etching of the bonding channel to $1.5 \mu \mathrm{m}$, (q) selective reactive ion etching (RIE) of the left oxide silicon layer.

Fabrication of the glass cover procedure was shown in Fig. 2r-x. Initially a photoresist layer was spun on the 7740 glass surface. After patterning with the photolithography technique, a titanium layer of $200 \AA$, a platinum layer of $1,500 \AA$ and a gold layer of 3,000 $\AA$ were sputtered successively on the glass surface. After the photolithograph process, the chemical etching technique was used to remove the gold film selectively, exposing the five platinum film heaters for seed bubble generations. Finally the glass cover and silicon substrate were bonded together. The microchannel surface was scanned by an AFM to have the roughness of $8.5 \mathrm{~nm}$.

\subsection{Experiment}

The experimental setup and measurement instruments are exactly identical to those of $\mathrm{Xu}$ et al. (2009). The five microheaters within microchannels are used for both seed bubble generations and temperature sensors to record temperature variations with respect to time. Data reductions involve mass flux $G$, liquid Reynolds number $R e$, heat flux at the main heater surface $q$, boiling number $B o$. All these parameters are described in $\mathrm{Xu}$ et al. (2009). It is noted that one would like to use another heat flux that is defined as the heating power applied on the total inside wall surface of microchannels, i.e., $q_{\mathrm{sw}}=Q /\left(N \cdot 2 \cdot W_{\mathrm{s}}\right.$. $L_{\mathrm{h}}$ ), where $Q$ is the effective heating power, $N$ is the number of parallel microchannels, $W_{\mathrm{s}}$ is the side wall width of microchannels, $L_{\mathrm{h}}$ is the effective heating length of microchannels. For the present design of heat transfer system, $q_{\mathrm{sw}}=0.817 q$. Acetone liquid was used as the working fluid. Physical properties are listed in Table 1 at atmospheric pressure (saturation condition), cited from Yaws (1999).

The pressure drop transducer has an accuracy of $0.1 \%$ with a response time of $0.1 \mathrm{~s}$. Thermocouples have an accuracy of $0.3^{\circ} \mathrm{C}$ with a response time of $0.1 \mathrm{~s}$. The syringe pump gives the flow rate reading having an accuracy of $1.0 \%$. Heating surface temperatures measured by the IR imaging system had an uncertainty of $0.5^{\circ} \mathrm{C}$ with a response time of $0.25 \mathrm{~s}$. Performing the standard error analysis yields uncertainties of mass flux of $1.2 \%$ and the liquid Reynolds number of $1.2 \%$.

The effective thermal efficiency $\phi$ was influenced by many factors. Heat loss of the microsystem includes not only radiation and natural convection heat transfer from the 
Fig. 2 The MEMS fabrication procedure (silicon: $\square Z$, silicon nitride: $\square$, photosensitive resist: $\square$, glass:, silicon oxide: $\square$, platinum: $\square$, Ti:, Au: $\square$, mask: $\square$ )

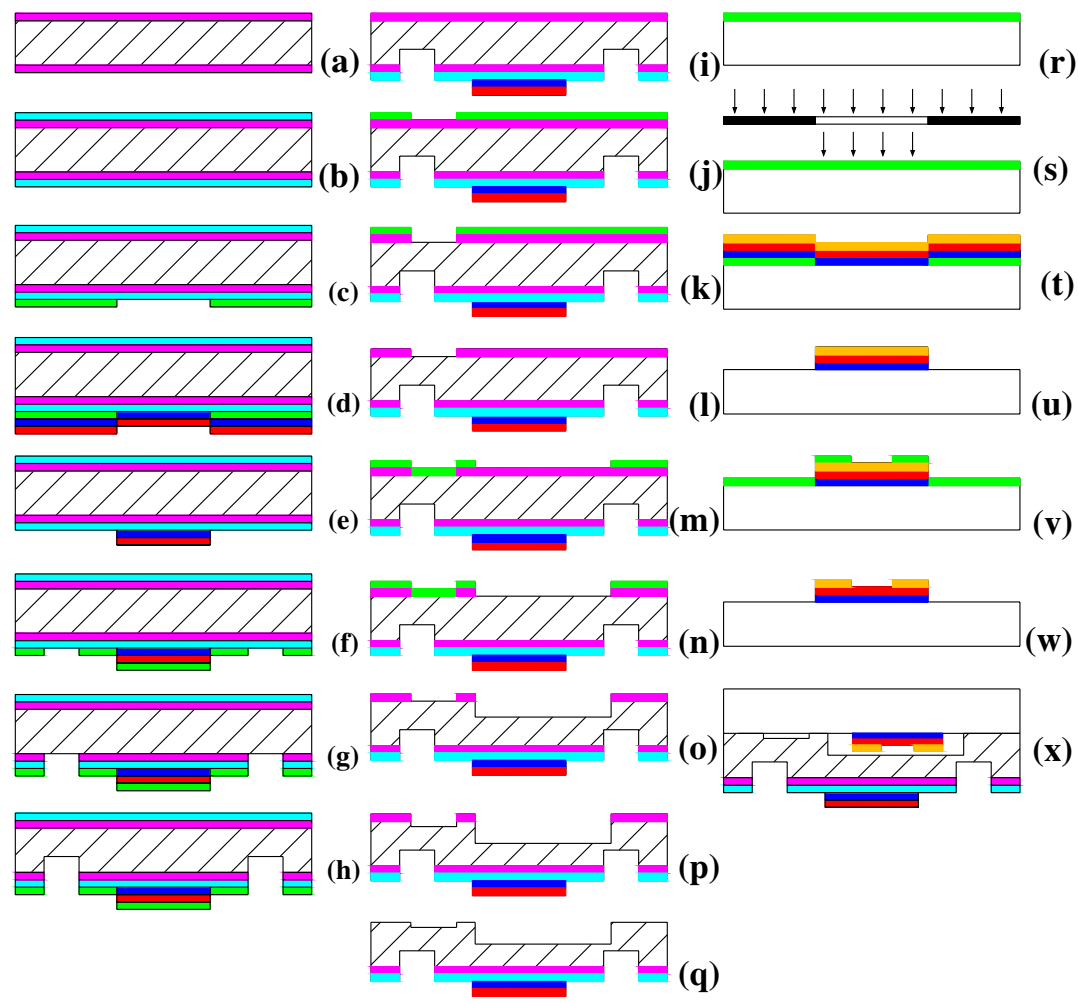

Table 1 Major physical properties of acetone at atmospheric pressure (saturation condition)

\begin{tabular}{llllllll}
\hline$T_{\text {sat }}\left({ }^{\circ} \mathrm{C}\right)$ & $\rho_{\mathrm{f}}\left(\mathrm{kg} / \mathrm{m}^{3}\right)$ & $C_{\mathrm{pf}}[\mathrm{J} /(\mathrm{kg} \mathrm{K})]$ & $C_{\mathrm{pg}}[\mathrm{J} /(\mathrm{kg} \mathrm{K})]$ & $h_{\mathrm{fg}}(\mathrm{kJ} / \mathrm{kg})$ & $\mu_{\mathrm{f}}(\mathrm{Pa} \mathrm{s})$ & $\mu_{\mathrm{g}}(\mathrm{Pa} \mathrm{s})$ & $k_{\mathrm{f}}[\mathrm{W} /(\mathrm{m} \mathrm{K})]$ \\
\hline 56.3 & 748.0 & 2302.5 & 1380.6 & 512.94 & $2.37 \times 10^{-4}$ & $8.31 \times 10^{-6}$ & 0.518 \\
\hline
\end{tabular}

$T_{\text {sat }}$ saturation temperature, $C_{\mathrm{pf}}$ and $C_{\mathrm{pg}}$ specific heat of liquid and vapor, $h_{\mathrm{fg}}$ latent heat of evaporation, $\mu_{\mathrm{f}}$ and $\mu_{\mathrm{g}}$ viscosity of liquid and vapor, $k_{\mathrm{f}}$ thermal conductivity of liquid

heated chip surface to environment, but also thermal conduction from the microsystem to its upstream and downstream connection tubes. A set of single-phase liquid flow experiment was performed to decide the thermal efficiency $\phi$, calculated as the heat received by acetone liquid (computed from mass flow rate and inlet/outlet fluid temperature difference) divided by the total applied heating power. The calibrations identified the highest thermal efficiency of 0.82 and the smallest value of 0.76 . Thus, we selected the average value of 0.79 , under which the maximum uncertainty of $\phi$ is $6.0 \%$. Giving the fact that the voltage measurement is very accurate, this estimation of $\phi$ directly leads to the uncertainty of heat flux of $6.0 \%$. It is found that the major parameters influencing the effective thermal efficiency are the applied heating power and heating surface temperature. Mass flow rates for the singlephase liquid flow are quite smaller than those for the twophase flow, and heat transfer coefficients in microchannels for the single-phase liquid flow are smaller than those for the two-phase flow. By adjusting the mass flow rate during the calibration experiment, one can obtain a similar heating surface temperature with that for a two-phase flow experiment when the same heating power is applied. In this way the effective thermal efficiency for the single-phase flow is roughly identical to that for the two-phase flow experiment. The calibration experiments maintain the similar ranges of applied heating powers and heating surface temperatures with those of two-phase flow.

\section{Experimental procedure}

The present study covers the following data ranges: mass fluxes of $378-898 \mathrm{~kg} /\left(\mathrm{m}^{2} \mathrm{~s}\right)$, heat fluxes of $267-778 \mathrm{~kW} / \mathrm{m}^{2}$. The seed bubble frequency $f$ is from 10 to $2,000 \mathrm{~Hz}$. Seed bubble sizes are from several to ten microns and can be varied by changing the pulse voltage amplitudes. Heat transfer performance is less affected by the seed bubble size. This is because the seed bubble growth is mainly fulfilled in the main heater region. Microheaters are only used to generate seed bubbles. The electric energy consumed by microheaters is very small compared with that 
generated on the main heater. The objective of this study is to observe how seed bubbles trigger boiling heat transfer. During each run, we set up a stable flow under heating condition on the main heater surface. Liquid in microchannels may be superheated but boiling is never initiated. We turn on the seed bubble generator to trigger boiling heat transfer. The seed bubble triggered boiling heat transfer state lasts more than $100 \mathrm{~s}$. Then the system returns to the state of the single-phase liquid flow by turning off the seed bubble generator. The measurement instruments collect data and image files for both seed bubble and no seed bubble conditions.

During the experiment, the high speed data acquisition system, the high speed camera and the IR imaging system were in the waiting mode. The synchronization hub sent a signal, triggering functions of these systems. The maximum time difference of the initial function of the three systems after they receive the triggering signal from the synchronization hub is smaller than $20 \mathrm{~ns}$. A central control computer collected all image files and data from the measurement systems.

\section{Results and discussion}

\subsection{Seed bubble generation}

$\mathrm{Xu}$ et al. (2009) describes the working principle of seed bubble generators. A seed bubble is produced during the pulse duration time and swept away from the microheater when the signal is temporarily off. Continuous pulse cycles generate a set of seed bubbles in time sequence. When seed bubbles contact liquid whose temperature is above the saturation value, seed bubbles will be growing up.

In order to generate seed bubbles, the voltage applied on the microheater array is gradually increased until miniature bubbles can be seen through the microscope. The time averaged electric energy consumed by the five microheaters, $Q_{\text {ave }}$, depends on the heat flux $q_{\mathrm{fi}}$, the pulse duration time $\tau_{\mathrm{d}}$ and the pulse cycle period $\tau(\tau=1 / f)$, which is calculated as

$Q_{\mathrm{ave}}=\frac{N \int_{0}^{\tau_{\mathrm{d}}} q_{\mathrm{fi}} L W \mathrm{~d} t}{\tau}=\mathrm{NLW} f \int_{0}^{\tau_{\mathrm{d}}} q_{\mathrm{fi}} \mathrm{d} t=f \int_{0}^{\tau_{\mathrm{d}}} Q(t) \mathrm{d} t$

The calculated $Q_{\text {ave }}$ are $0.35,3.5,17.5,70$ and $105 \mathrm{~mW}$ for $f=1,10,100,1,000$ and $2,000 \mathrm{~Hz}$, respectively. These values are very small compared with the heat load in the main heater at the back silicon surface. The liquid temperature rise in the seed bubble generation process is estimated to be $0.006,0.06,0.3,1.2$ and $1.8^{\circ} \mathrm{C}$ for $f=1$, $10,100,1,000$ and $2,000 \mathrm{~Hz}$, respectively. It is neglectable for $f<100 \mathrm{~Hz}$ but it has a couple of degrees for $f=1,000-2,000 \mathrm{~Hz}$.

\subsection{Seed bubble triggered boiling heat transfer in microchannels}

For each run, the micro heat transfer system operated for wall superheats $\Delta T_{\text {sup,max }}=T_{\text {film,max }}-T_{\text {sat }}<15^{\circ} \mathrm{C}$, ensuring no bubbles in microchannels everywhere. Liquid in microchannels may be superheated. Injection seed bubbles triggers boiling heat transfer and induces four modes of flow and heat transfer. We consider parameters affecting transition boundaries among the four modes of flow and heat transfer. Inlet liquid temperatures did not changed too much. Mass flux $G$ and heat flux $q$ on the main heating area are the two important parameters. They are combined to form the boiling number, i.e., $B o=q /\left(G h_{\mathrm{fg}}\right)$. We found that seed bubble frequency, identical to the pulse signal frequency, also significantly influences flow and heat transfer in microchannels. Thus, regimes of the four modes of seed bubble triggered heat transfer depend on boiling number $B o$ and seed bubble frequency $f$, which are shown in Fig. 3, summarized as follows:

- Mode 1: appears at boiling numbers smaller than $1.7 \times 10^{-3}$ with low seed bubble frequency such as $f=10 \mathrm{~Hz}$.

- Mode 2: appears at boiling numbers smaller than $1.5 \times 10^{-3}$ with seed bubble frequencies from 100 to $2,000 \mathrm{~Hz}$.

- Mode 3: appears at boiling numbers in the range of $1.6-1.8 \times 10^{-3}$ with any seed bubble frequencies.

- Mode 4: appears at boiling numbers larger than $1.85 \times 10^{-3}$ with any seed bubble frequencies.

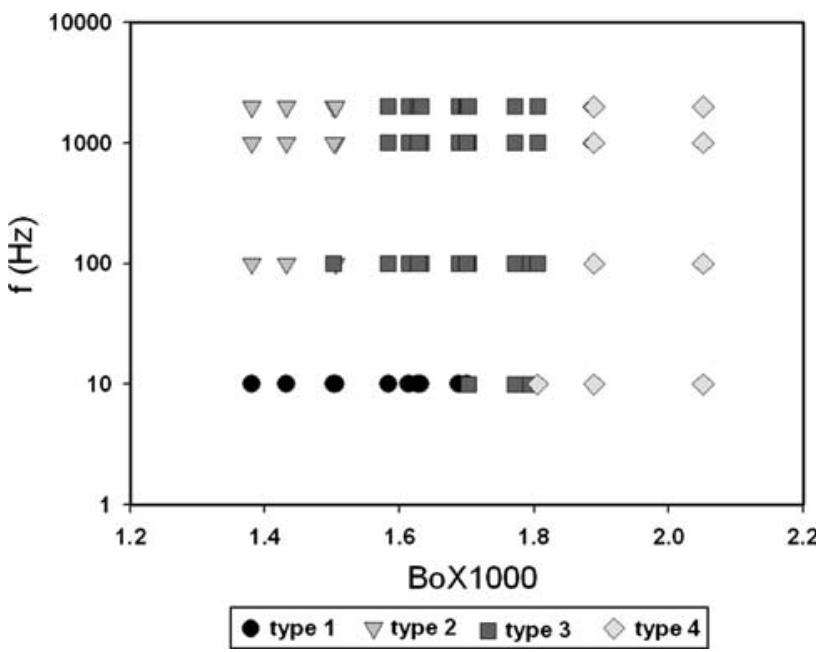

Fig. 3 Regimes for the four types of seed bubble triggered boiling heat transfer 
Table 2 Runs performed in this study

\begin{tabular}{|c|c|c|c|c|c|c|c|c|c|c|c|}
\hline Run & $G\left[\mathrm{~kg} /\left(\mathrm{m}^{2} \mathrm{~s}\right)\right]$ & $q\left(\mathrm{~kW} / \mathrm{m}^{2}\right)$ & $T_{\text {in }}\left({ }^{\circ} \mathrm{C}\right)$ & $T_{\text {out }}\left({ }^{\circ} \mathrm{C}\right)$ & $f(\mathrm{~Hz})$ & $R \mathrm{e}$ & $u_{\text {ave }}(\mathrm{m} / \mathrm{s})$ & $B \mathrm{o} \times 1,000$ & Mode & $\tau_{\mathrm{c}}(\mathrm{s})$ & $\delta_{\mathrm{p}}(\mathrm{kPa})$ \\
\hline 1 & 377.9 & 267.6 & 3.4 & 38.7 & 10 & 164.2 & 0.51 & 1.381 & 1 & $x$ & $\times$ \\
\hline 2 & 377.9 & 267.8 & 3.1 & 39.5 & 100 & 164.2 & 0.51 & 1.382 & 2 & $\times$ & $\times$ \\
\hline 3 & 377.9 & 268.0 & 3.3 & 39.8 & 1,000 & 164.2 & 0.51 & 1.383 & 2 & $\times$ & $\times$ \\
\hline 4 & 377.9 & 268.0 & 3.6 & 39.9 & 2,000 & 164.2 & 0.51 & 1.383 & 2 & $\times$ & $x$ \\
\hline 5 & 377.9 & 315.5 & 2.8 & 42.1 & 10 & 164.2 & 0.51 & 1.628 & 1 & $x$ & $\times$ \\
\hline 6 & 377.9 & 316.3 & 2.8 & 42.6 & 100 & 164.2 & 0.51 & 1.631 & 3 & 34.5 & 1.21 \\
\hline 7 & 377.9 & 316.4 & 3.2 & 43.0 & 1,000 & 164.2 & 0.51 & 1.632 & 3 & 24.2 & 1.82 \\
\hline 8 & 377.9 & 316.1 & 4.5 & 45.3 & 2,000 & 164.2 & 0.51 & 1.631 & 3 & 25.3 & 1.61 \\
\hline 9 & 377.9 & 366.2 & 4.7 & 47.7 & 10 & 164.2 & 0.51 & 1.889 & 2 & $\times$ & $\times$ \\
\hline 10 & 377.9 & 367.6 & 5.0 & 49.3 & 100 & 164.2 & 0.51 & 1.896 & 4 & $x$ & $\times$ \\
\hline 11 & 377.9 & 368.01 & 4.7 & 47.4 & 1,000 & 164.2 & 0.51 & 1.898 & 4 & $\times$ & $\times$ \\
\hline 12 & 377.9 & 368.63 & 4.8 & 48.3 & 2,000 & 164.2 & 0.51 & 1.902 & 4 & $\times$ & $\times$ \\
\hline 13 & 377.9 & 395.23 & 5.4 & 49.3 & 10 & 164.2 & 0.51 & 2.039 & 4 & $x$ & $\times$ \\
\hline 14 & 377.9 & 396.72 & 5.5 & 51.7 & 100 & 164.2 & 0.51 & 2.047 & 4 & $\times$ & $\times$ \\
\hline 15 & 377.9 & 397.24 & 5.6 & 51.9 & 1,000 & 164.2 & 0.51 & 2.049 & 4 & $\times$ & $\times$ \\
\hline 16 & 377.9 & 397.55 & 5.7 & 52.2 & 2,000 & 164.2 & 0.51 & 2.051 & 4 & $\times$ & $\times$ \\
\hline 17 & 598.4 & 461.06 & 3.2 & 41.9 & 10 & 260.2 & 0.80 & 1.502 & 1 & $\times$ & $x$ \\
\hline 18 & 598.4 & 461.88 & 3.4 & 42.7 & 100 & 260.2 & 0.80 & 1.505 & 3 & 28.8 & 3.10 \\
\hline 19 & 598.4 & 462.41 & 3.1 & 43.0 & 1,000 & 260.2 & 0.80 & 1.507 & 2 & $\times$ & $\times$ \\
\hline 20 & 598.4 & 462.36 & 3.0 & 42.8 & 2,000 & 260.2 & 0.80 & 1.506 & 2 & $\times$ & $\times$ \\
\hline 21 & 598.4 & 494.40 & 2.1 & 44.0 & 10 & 260.2 & 0.80 & 1.611 & 1 & $\times$ & $\times$ \\
\hline 22 & 598.4 & 495.38 & 2.1 & 44.1 & 100 & 260.2 & 0.80 & 1.614 & 3 & 14.4 & 2.20 \\
\hline 23 & 598.4 & 492.79 & 2.3 & 44.0 & 1,000 & 260.2 & 0.80 & 1.605 & 3 & 28.8 & 3.40 \\
\hline 24 & 598.4 & 492.38 & 2.4 & 45.1 & 2,000 & 260.2 & 0.80 & 1.604 & 3 & 22.1 & 3.95 \\
\hline 25 & 598.4 & 521.08 & 2.8 & 45.9 & 10 & 260.2 & 0.80 & 1.698 & 1 & $x$ & $\times$ \\
\hline 26 & 598.4 & 521.70 & 3.0 & 45.9 & 100 & 260.2 & 0.80 & 1.700 & 3 & 9.1 & 2.30 \\
\hline 27 & 598.4 & 521.66 & 3.1 & 47.9 & 1,000 & 260.2 & 0.80 & 1.700 & 3 & 11.4 & 4.21 \\
\hline 28 & 598.4 & 521.77 & 3.3 & 46.9 & 2,000 & 260.2 & 0.80 & 1.700 & 3 & 10.5 & 3.62 \\
\hline 29 & 598.4 & 553.23 & 3.1 & 47.9 & 10 & 260.2 & 0.80 & 1.803 & 4 & $\times$ & $\times$ \\
\hline 30 & 598.4 & 553.99 & 3.0 & 48.1 & 100 & 260.2 & 0.80 & 1.805 & 3 & 7.8 & 2.10 \\
\hline 31 & 598.4 & 554.99 & 3.1 & 48.4 & 1,000 & 260.2 & 0.80 & 1.808 & 3 & 10.9 & 4.43 \\
\hline 32 & 598.4 & 555.09 & 3.3 & 47.1 & 2,000 & 260.2 & 0.80 & 1.809 & 3 & 6.9 & 2.21 \\
\hline 33 & 755.9 & 632.23 & 3.8 & 47.5 & 10 & 328.5 & 1.01 & 1.631 & 3 & 8.8 & 1.37 \\
\hline 34 & 755.9 & 632.47 & 3.9 & 47.2 & 100 & 328.5 & 1.01 & 1.631 & 3 & 8.1 & 1.85 \\
\hline 35 & 755.9 & 635.25 & 3.7 & 47.0 & 1,000 & 328.5 & 1.01 & 1.638 & 3 & 20.4 & 4.95 \\
\hline 36 & 755.9 & 634.51 & 3.7 & 47.5 & 2,000 & 328.5 & 1.01 & 1.636 & 3 & 6.9 & 1.22 \\
\hline 37 & 755.9 & 660.18 & 3.0 & 48.4 & 10 & 328.5 & 1.01 & 1.703 & 3 & 8.7 & 1.52 \\
\hline 38 & 755.9 & 661.00 & 3.2 & 48.6 & 100 & 328.5 & 1.01 & 1.704 & 3 & 9.6 & 2.45 \\
\hline 39 & 755.9 & 661.49 & 3.4 & 49.0 & 1,000 & 328.5 & 1.01 & 1.706 & 3 & 9.3 & 4.12 \\
\hline 40 & 755.9 & 661.01 & 3.7 & 49.1 & 2,000 & 328.5 & 1.01 & 1.704 & 3 & 6.7 & 1.71 \\
\hline 41 & 755.9 & 695.70 & 4.0 & 50.9 & 10 & 328.5 & 1.01 & 1.794 & 3 & 6.1 & 0.9 \\
\hline 42 & 755.9 & 696.41 & 3.8 & 51.1 & 100 & 328.5 & 1.01 & 1.796 & 3 & 5.7 & 1.98 \\
\hline 43 & 755.9 & 697.91 & 3.4 & 50.7 & 1,000 & 328.5 & 1.01 & 1.799 & 4 & $\times$ & $\times$ \\
\hline 44 & 755.9 & 697.13 & 2.9 & 50.1 & 2,000 & 328.5 & 1.01 & 1.797 & 4 & $\times$ & $\times$ \\
\hline 45 & 755.9 & 731.79 & 2.9 & 52.8 & 10 & 328.5 & 1.01 & 1.888 & 4 & $\times$ & $\times$ \\
\hline 46 & 755.9 & 732.63 & 2.9 & 51.9 & 100 & 328.5 & 1.01 & 1.889 & 3 & 5.9 & 2.14 \\
\hline 47 & 755.9 & 733.00 & 2.9 & 51.6 & 1,000 & 328.5 & 1.01 & 1.890 & 4 & $\times$ & $\times$ \\
\hline 48 & 755.9 & 733.01 & 3.1 & 52.1 & 2,000 & 328.5 & 1.01 & 1.890 & 4 & $\times$ & $x$ \\
\hline
\end{tabular}


Table 2 continued

\begin{tabular}{lllllrllllll}
\hline Run & $G\left[\mathrm{~kg} /\left(\mathrm{m}^{2} \mathrm{~s}\right)\right]$ & $q\left(\mathrm{~kW} / \mathrm{m}^{2}\right)$ & $T_{\text {in }}\left({ }^{\circ} \mathrm{C}\right)$ & $\left.T_{\text {out }}{ }^{\circ} \mathrm{C}\right)$ & $f(\mathrm{~Hz})$ & $R \mathrm{e}$ & $u_{\text {ave }}(\mathrm{m} / \mathrm{s})$ & $B$ o $\times 1,000$ & $\mathrm{Mode}$ & $\tau_{\mathrm{c}}(\mathrm{s})$ & $\delta_{\mathrm{p}}(\mathrm{kPa})$ \\
\hline 49 & 897.6 & 659.17 & 5.0 & 43.0 & 10 & 390.3 & 1.20 & 1.432 & 1 & $\times$ & $\times$ \\
50 & 897.6 & 659.77 & 4.9 & 43.8 & 100 & 390.3 & 1.20 & 1.433 & 2 & $\times$ & $\times$ \\
51 & 897.6 & 660.38 & 4.8 & 44.2 & 1,000 & 390.3 & 1.20 & 1.434 & 2 & $\times$ & $\times$ \\
52 & 897.6 & 660.28 & 4.7 & 44.0 & 2,000 & 390.3 & 1.20 & 1.434 & 2 & $\times$ & $\times$ \\
53 & 897.6 & 692.55 & 4.0 & 44.2 & 10 & 390.3 & 1.20 & 1.504 & 2 & $\times$ & $\times$ \\
54 & 897.6 & 693.39 & 3.5 & 44.2 & 100 & 390.3 & 1.20 & 1.506 & 2 & $\times$ & $\times$ \\
55 & 897.6 & 693.54 & 3.4 & 44.5 & 1,000 & 390.3 & 1.20 & 1.506 & 2 & $\times$ \\
56 & 897.6 & 693.59 & 3.3 & 44.1 & 2,000 & 390.3 & 1.20 & 1.507 & 2 & $\times$ \\
57 & 897.6 & 729.17 & 4.0 & 46.1 & 10 & 390.3 & 1.20 & 1.584 & 1 & $\times$ \\
58 & 897.6 & 730.46 & 3.9 & 46.9 & 100 & 390.3 & 1.20 & 1.587 & 3 & 4.2 & 0.86 \\
59 & 897.6 & 731.25 & 4.0 & 46.3 & 1,000 & 390.3 & 1.20 & 1.588 & 3 & 4.5 & 0.91 \\
60 & 897.6 & 725.83 & 4.1 & 46.3 & 2,000 & 390.3 & 1.20 & 1.577 & 3 & 4.2 & 0.76 \\
61 & 897.6 & 777.29 & 4.0 & 47.8 & 10 & 390.3 & 1.20 & 1.688 & 1 & $\times$ \\
62 & 897.6 & 778.01 & 3.7 & 46.8 & 100 & 390.3 & 1.20 & 1.690 & 3 & 11.9 & 4.21 \\
63 & 897.6 & 776.55 & 3.6 & 47.4 & 1,000 & 390.3 & 1.20 & 1.687 & 3 & 7.4 & 4.62 \\
64 & 897.6 & 776.63 & 3.6 & 47.3 & 2,000 & 390.3 & 1.20 & 1.687 & 3 & 12.7 & 5.97 \\
\hline
\end{tabular}

$\tau_{\mathrm{c}}$ is the oscillation cycle period of the system that is different from the pulse cycle period for seed bubble generations, $\delta_{\mathrm{p}}$ is the oscillation amplitude for pressure drop. These two values are only given for the mode 3 heat transfer

Fig. 4 Variations of pressure drop, fluid inlet and outlet temperatures, heating surface temperatures without and with seed bubbles $(f=10 \mathrm{~Hz})$ for $G=377.9 \mathrm{~kg} /\left(\mathrm{m}^{2} \mathrm{~s}\right)$, $q=315.5 \mathrm{~kW} / \mathrm{m}^{2}$,

Bo $=0.001626$ (mode 1 seed bubble triggered heat transfer)

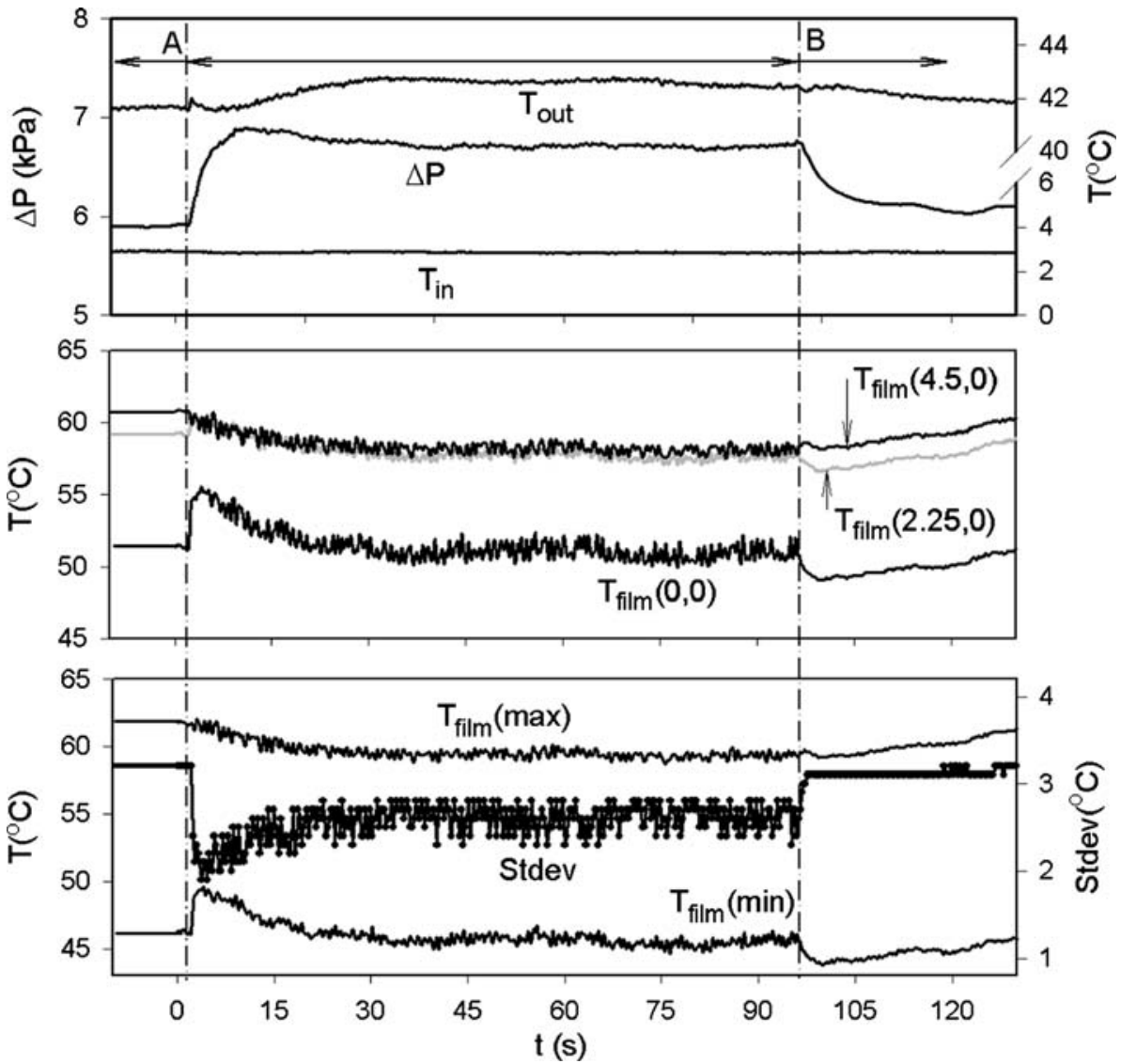

If boiling numbers are beyond the scope shown in Fig. 3, i.e., $B o>2.1 \times 10^{-3}$, self-boiling heat transfer is sustained in microchannels, which is beyond the present paper scope. Table 2 gave the 64 runs that were performed in the present paper. Regarding the four modes of flow and heat transfer, modes 1, 2, and 4 are stable ones. But mode 3 
Fig. 5 Flow pattern for mode 1 seed bubble triggered heat transfer, $\mathbf{a}$ and $\mathbf{b}$ transient flow patterns in channels \#1 and 3; c displacement of bubbles or rear elongated bubble interface versus time

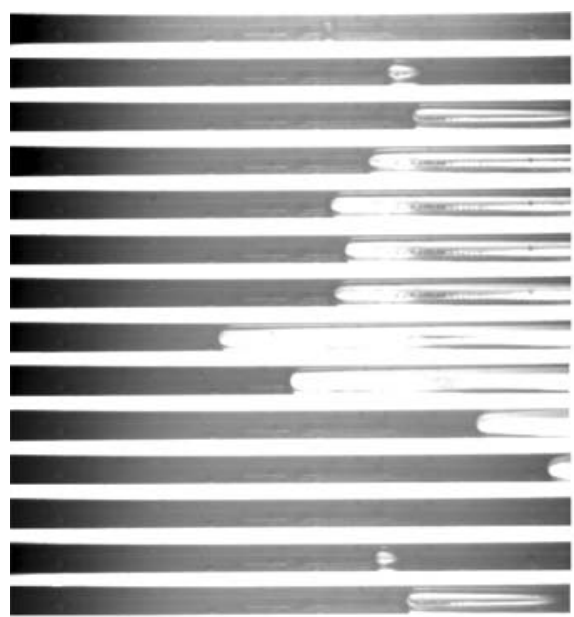

(a) $\mathrm{Ch} \# 1$

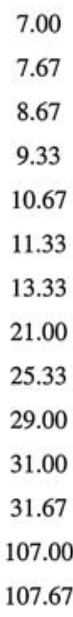

$t$ (ms)

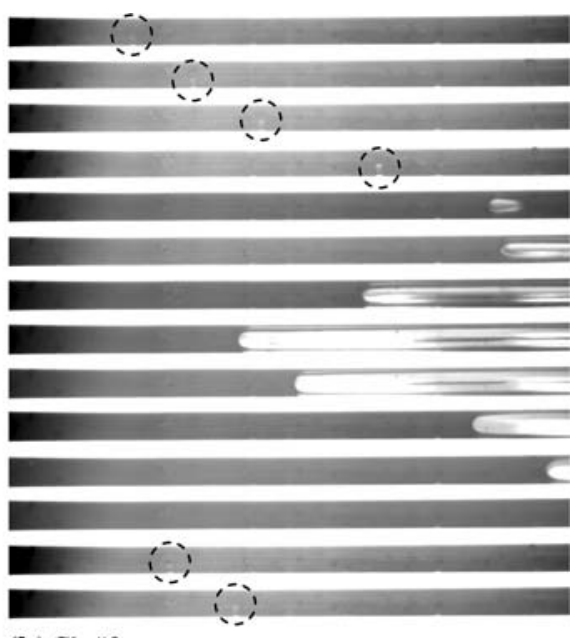

(b) $\mathrm{Ch} \# 3$

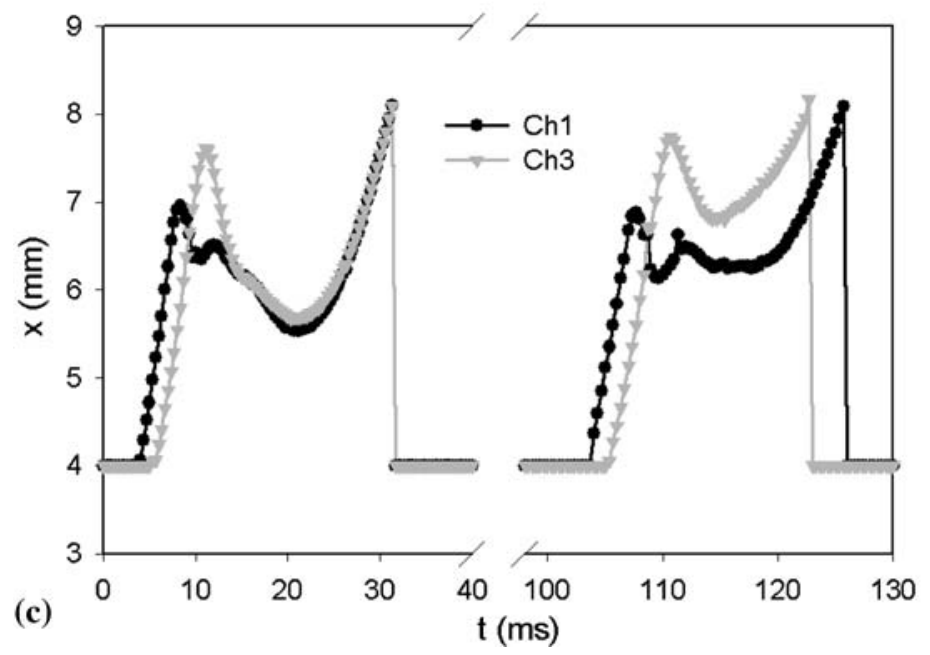

is the unstable one with apparent oscillating amplitudes and long cycle periods of heating surface temperatures. For such runs, oscillating amplitude of pressure drop was given which is defined as the pressure drop difference between maximum and minimum for each cycle. Oscillating cycle periods in Table 2 refer to those of the heat transfer system triggered by seed bubbles, which are different from the pulse cycle periods $(\tau=1 / f)$ of seed bubbles.

\subsubsection{Mode 1 seed bubble triggered heat transfer}

Figure 4 shows various parameters versus time before and after triggering seed bubbles for $G=377.9 \mathrm{~kg} /\left(\mathrm{m}^{2} \mathrm{~s}\right)$, $q=315.5 \mathrm{~kW} / \mathrm{m}^{2}, B \mathrm{o}=0.001626$ and $f=10 \mathrm{~Hz}$. The system was running in the stable liquid flow state for $t<t_{\mathrm{A}}$ and the seed bubble triggered heat transfer state for $t_{\mathrm{A}}<t<t_{\mathrm{B}}$. It returned to the liquid flow state after turning off seed bubbles for $t>t_{\mathrm{B}}$. After triggering seed bubbles, fluid inlet temperatures $\left(T_{\text {in }}\right)$ did not change. Outlet fluid temperatures $\left(T_{\text {out }}\right)$ had a slight increase, but still lower than the saturation temperature of $56.3^{\circ} \mathrm{C}$ at atmospheric pressure. This is because the outlet vapor mass quality is small. Heat loss through the outlet connection tube quickly condenses vapor and decreases the outlet fluid temperature to be lower than the saturation temperature. Pressure drop $(\Delta p)$ was increased from $5.9 \mathrm{kPa}$ for liquid flow to $6.7 \mathrm{kPa}$ for two-phase flow after triggering seed bubbles. Temperatures at three locations of $(0,0),(2.25 \mathrm{~mm}, 0)$, and $(4.5 \mathrm{~mm}, 0)$ were given. These locations are defined in terms of the coordinate system attached on the main heating area $(4,500 \times 1,366 \mu \mathrm{m})$, on which temperature difference in the chip width direction is generally small. $T_{\text {film }}(2.25,0)$ and $T_{\text {film }}(4.5,0)$ are decreased by $2-3^{\circ} \mathrm{C}$ after triggering seed bubbles. However, $T_{\text {film }}(0,0)$ had a sharp increase to about $55^{\circ} \mathrm{C}$. During the initial transition stage, vapor growth in microchannels decreases mass flow rate. Vapor mass qualities are continuously increased until fresh liquid from the microchannel inlet re-enters microchannels. Then chip temperatures are found to oscillate with very small amplitudes. The oscillation timescale matches that 
Fig. 6 Temperatures at the heating area $(4,500 \times 1,366 \mu \mathrm{m})$ by the IR imaging measurement, and temperatures at the centerline of the heating area without and with seed bubbles assisted (mode 1 seed bubble triggered heat transfer) (a)
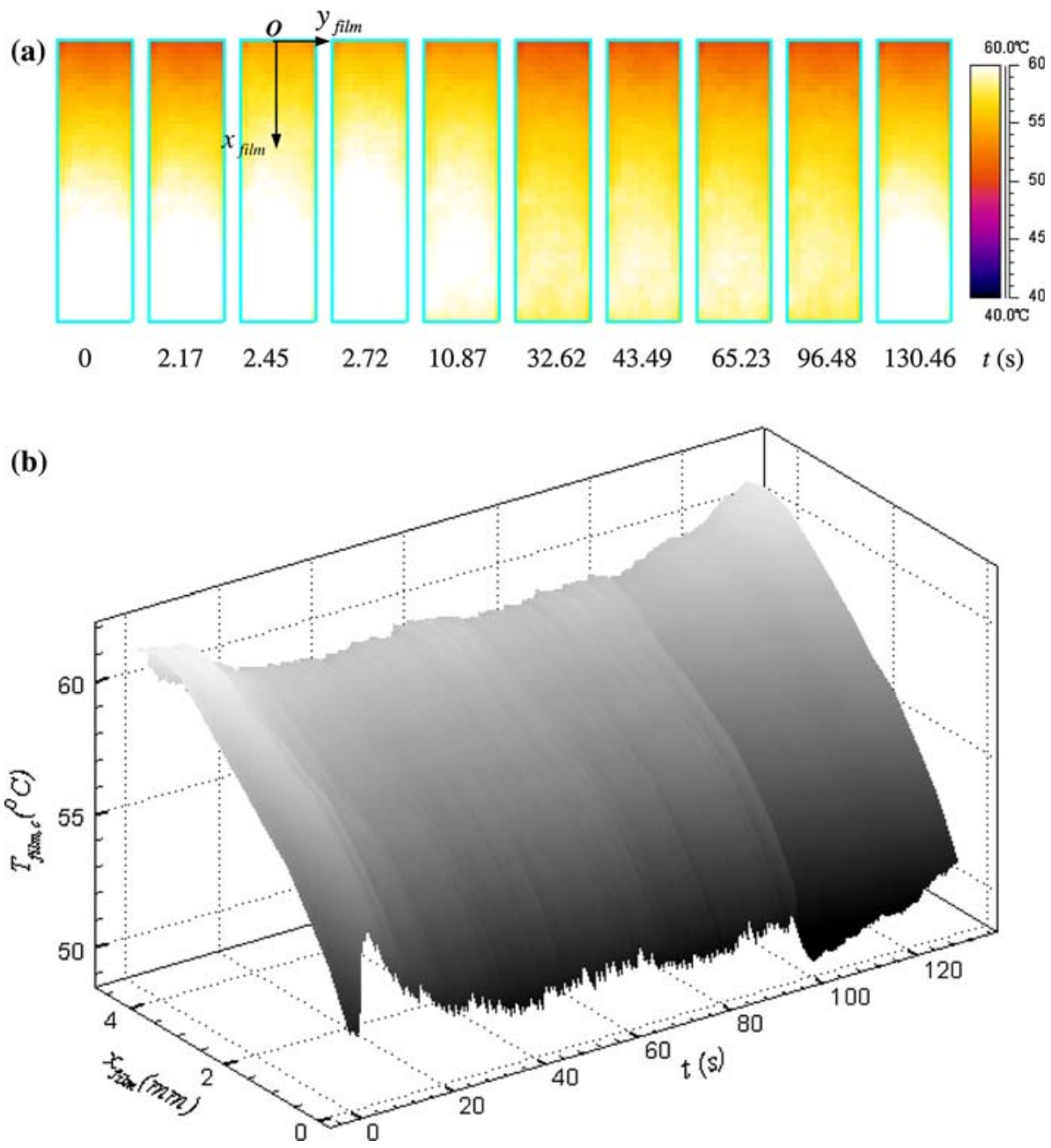

for the seed bubble generation. Maximum and minimum chip temperatures at the heating area were given, with maximum value decreased by a couple of degrees by triggering seed bubbles. The SD number (defined in $\mathrm{Xu}$ et al. 2009) was decreased from 3.2 to $2.5^{\circ} \mathrm{C}$ after triggering seed bubbles, indicating the improved uniformity of heating surface temperatures.

The seed bubble triggered heat transfer of this mode corresponds to the alternating liquid and elongated bubble flow in microchannels. The switch frequency for the flow pattern transition is exactly identical to the seed bubble frequency. Figure 5a, b shows the alternating liquid and elongated bubble flow in channels \#1 and 3. When a seed bubble reaches $x=6.8 \mathrm{~mm}$ at $t=7.67 \mathrm{~ms}$, it is growing to form an elongated bubble, expanding in both downstream and upstream directions (Fig. 5a). Because the channel downstream for $x>8 \mathrm{~mm}$ was out of the image recording area, tracking the front interface of elongated bubble was impossible. The rear interface of elongated bubble expanded to the channel upstream of $x=5.4 \mathrm{~mm}$ at $t=21 \mathrm{~ms}$, but it was pushed downstream again. Liquid flow was in the channel \#1 for $32 \mathrm{~ms}<t<103 \mathrm{~ms}$. Then the channel \#1 repeated evolution of seed bubble growth and elongated bubble expansion. Figure 5b shows similar flow pattern transitions in the channel \#3. The general trend for flow pattern transition is similar, but not exactly identical to the channel \#1. The circled bubble is the seed bubble before it had apparent growth to elongated bubble in Fig. 5b. Figure 5c gave the rear interfaces of bubbles, including a linear section for seed bubbles traveling in channels without apparent growth, and a parabola distribution corresponding to elongated bubble expansion in both downstream and upstream directions. The curves repeated periodically based on the pulse cycle period, i.e., $\tau=1 / f=100 \mathrm{~ms}$ for this run.

Figure 6a shows the heating surface temperatures $(4,500 \times 1,366 \mu \mathrm{m})$ by the IR imaging system, including three stages of before, after and re-turning off the pulse voltage signal. Triggering seed bubbles involves an initial slightly increased temperatures for $2.17<t<10.87 \mathrm{~s}$. After that the steadily sustained heat transfer decreased heating surface temperatures to be lower than the values 
Fig. 7 Variations of pressure drop, fluid inlet and outlet temperatures, and heating surface temperatures without and with triggering seed bubbles for $G=598.4 \mathrm{~kg} /\left(\mathrm{m}^{2} \mathrm{~s}\right)$, $q=462.4 \mathrm{~kW} / \mathrm{m}^{2}$, Bo $=0.001435, f=2,000 \mathrm{~Hz}$ (mode 2 seed bubble triggered heat transfer)
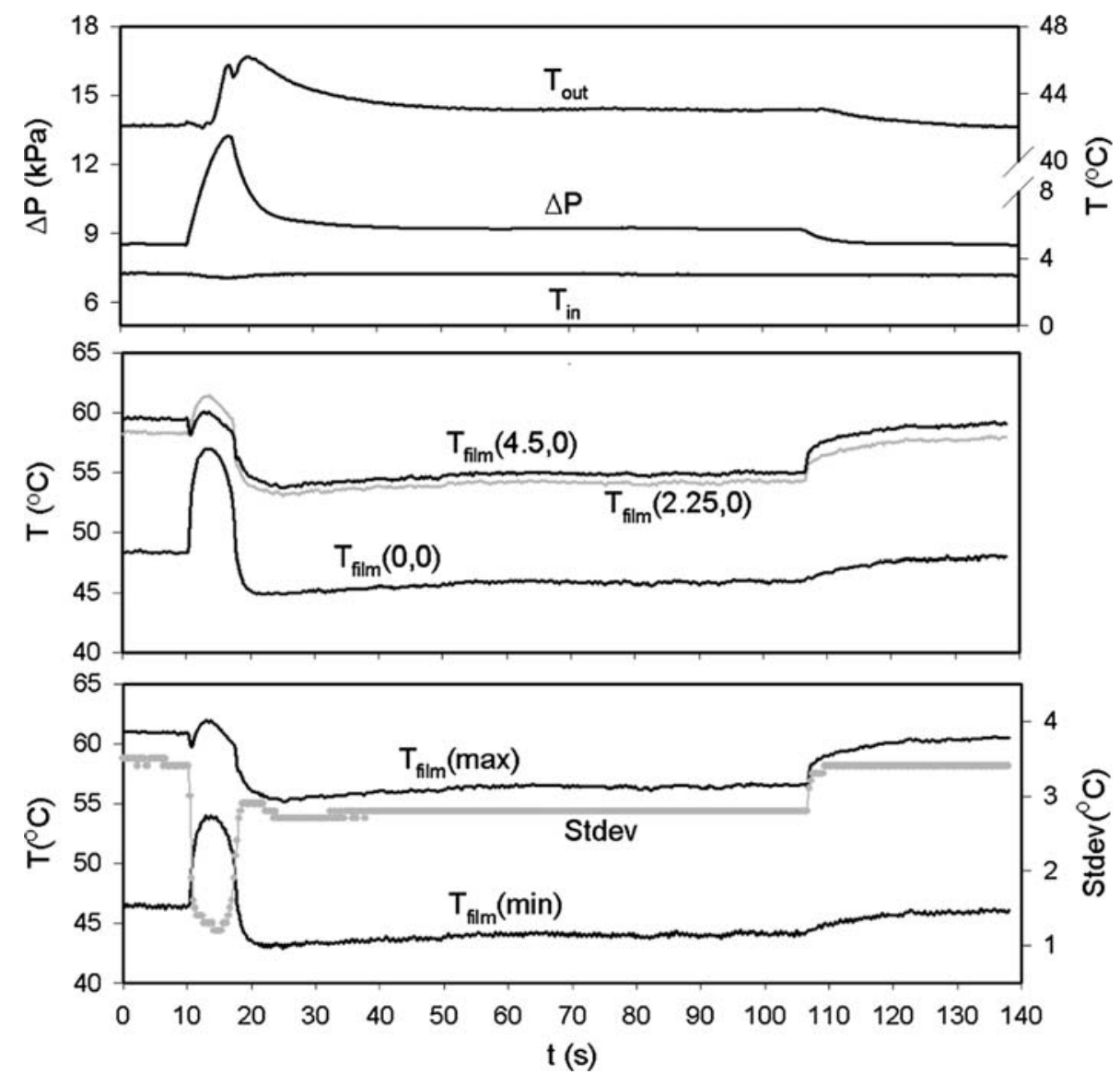

before triggering seed bubbles. Figure $6 \mathrm{~b}$ shows temperatures at the centerline of heating surface, i.e., $T_{\text {film,c }}$, versus time. The sofa shape temperature distribution indicates that seed bubbles successfully trigger boiling incipience and decrease heating surface temperatures.

\subsubsection{Mode 2 seed bubble triggered heat transfer}

This mode of seed bubble guided heat transfer in microchannels takes place at low boiling numbers, with seed bubble frequencies larger than $100 \mathrm{~Hz}$. Pressure drop, fluid inlet/outlet temperatures and heating surface temperatures have similar responses as those of the mode 1. But they are very stable without any oscillations (Fig. 7). Heating surface temperatures are decreased by $5-6^{\circ} \mathrm{C}$ after triggering seed bubbles. Flow patterns in microchannels are thoroughly different from those of mode 1 . Figure $8 \mathrm{a}$ indicates growth of the circled seed bubble. The elongated bubble is not formed until it is out of the visualization area. Figure $8 \mathrm{~b}$ tracks displacements of two seed bubbles versus time in channels \#1 and 3, showing quasi-linear distributions. The triangular data is for channel \#1 and circular data for channel \#3. Gradients of $x$ with respect to time $t$ are the seed bubble velocities, which are slightly increased, caused by accelerations of the two-phase mixture due to continuous expansion.

With increases in seed bubble frequencies, more energy can be released from superheated liquid to vapor. Thus, heating surface temperatures are decreased more than those for the mode 1. Figure 9 gave the sofa shape temperature distribution at the centerline of the main heating surface.

\subsubsection{Mode 3 seed bubble triggered heat transfer}

This mode of seed bubble triggered heat transfer takes place at moderate boiling numbers. Pulse signal frequencies can be low or high (see Fig. 3). Running parameters shown in Figs. 10 and 11 are $G=377.9 \mathrm{~kg} /\left(\mathrm{m}^{2} \mathrm{~s}\right)$, $q=316.4 \mathrm{~kW} / \mathrm{m}^{2}, \quad B o=0.001634$ and $f=1,000 \mathrm{~Hz}$. Flow and heat transfer are absolutely stable for the singlephase liquid flow before triggering seed bubbles. After triggering seed bubbles, the system evolves an initial transition stage and then sustains oscillations with apparent amplitudes and long periods of pressure drops and heating surface temperatures. Pressure drop had the oscillation amplitude of $1.82 \mathrm{kPa}$, with the cycle period of $24.2 \mathrm{~s}$. Inlet and outlet fluid temperatures are oscillating with the 
Fig. 8 Flow pattern for mode 2 seed bubble triggered heat transfer, a seed bubble train in the channel \#1, $\mathbf{b}$ displacement of growing seed bubbles versus time

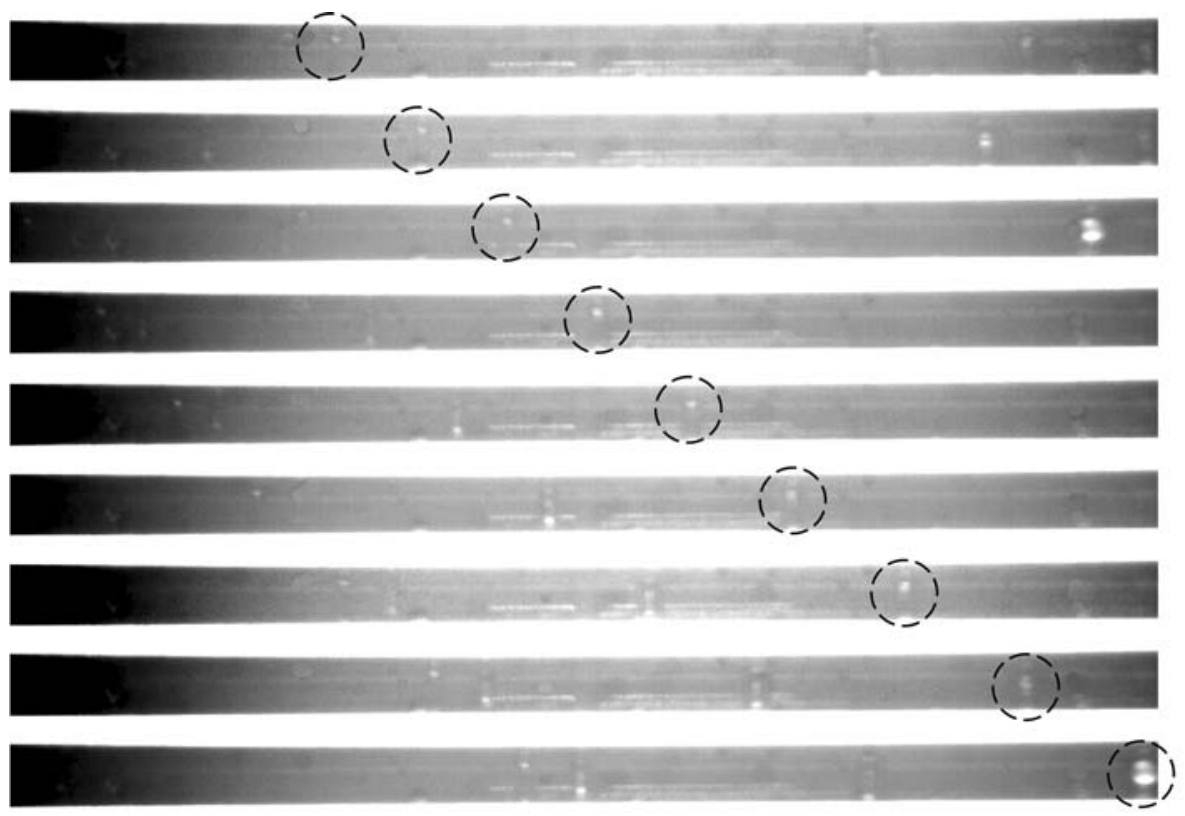

(a) $\mathrm{Ch} \# 1$

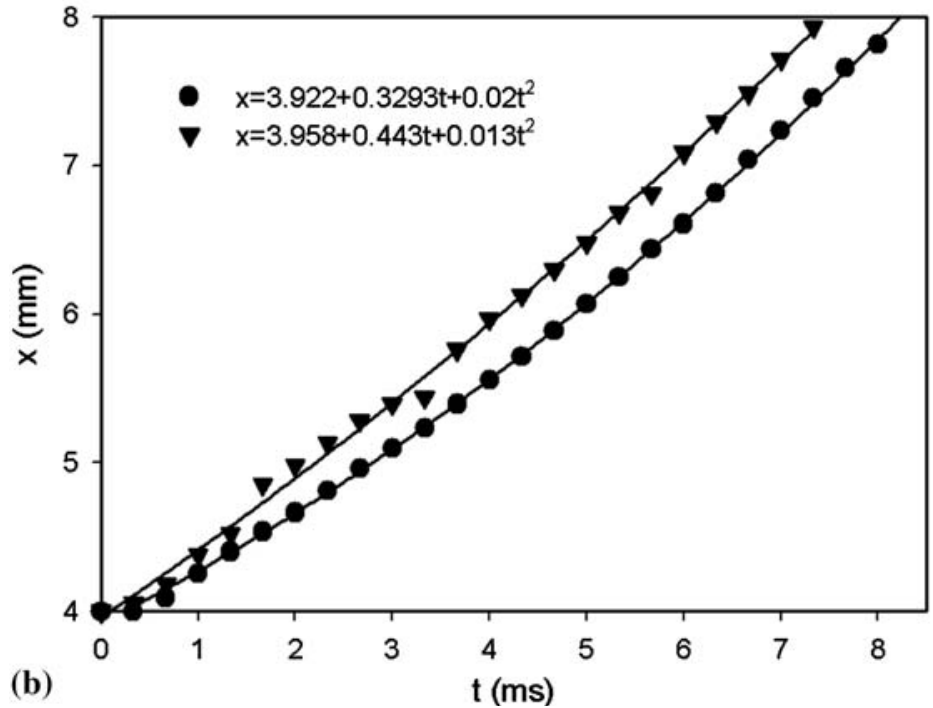

same cycle period as that of pressure drop but the amplitudes are small. Heating surface temperatures are decreased after triggering seed bubbles but they are oscillating with the amplitudes of $5-7^{\circ} \mathrm{C}$, depending on different locations on the main heating surface. The SD values are decreased but oscillate periodically.

Because cycle period is in several tens of seconds, flow pattern images are taken with low recording rate of 30 frames per second. Figure 11a shows the alternating bubble flow and elongated bubble flow for channel \#1. Flow pattern in other channels is roughly identical to that in channel $\# 1$. The channel \#1 had bubbles at $t=18 \mathrm{~s}$. Seed bubble growth and elongated bubble formation can be seen from 27.5 to $35 \mathrm{~s}$, during which elongated bubbles had maximum length at $t=31 \mathrm{~s}$, at which heating surface temperatures attain maximum values (see Fig. 10). One cycle is complete from 18 to $42.2 \mathrm{~s}$, with the cycle period of $24.2 \mathrm{~s}$, consistent with that determined by pressure drop and temperature variations shown in Fig. 10. A new cycle starts from $t=42.2 \mathrm{~s}$ and ends at $t=63 \mathrm{~s}$. Two elongated bubbles can be merged to form a longer one. The system behaves the typical flow pattern transition instability. Oscillation cycle period of the system is different from the pulse cycle period for seed bubble generations. This is the major difference between modes 1 and 3 seed bubble triggered heat transfer. The system returns to the singlephase superheated liquid flow if the pulse voltage signal is turned off. The seed bubble triggered oscillating flow of 
Fig. 9 Temperatures at the heating area $(4,500 \times 1,366 \mu \mathrm{m})$ by the IR imaging measurement, and temperatures at the centerline of the heating area before and after triggering seed bubbles (mode 2 seed bubble triggered heat transfer)

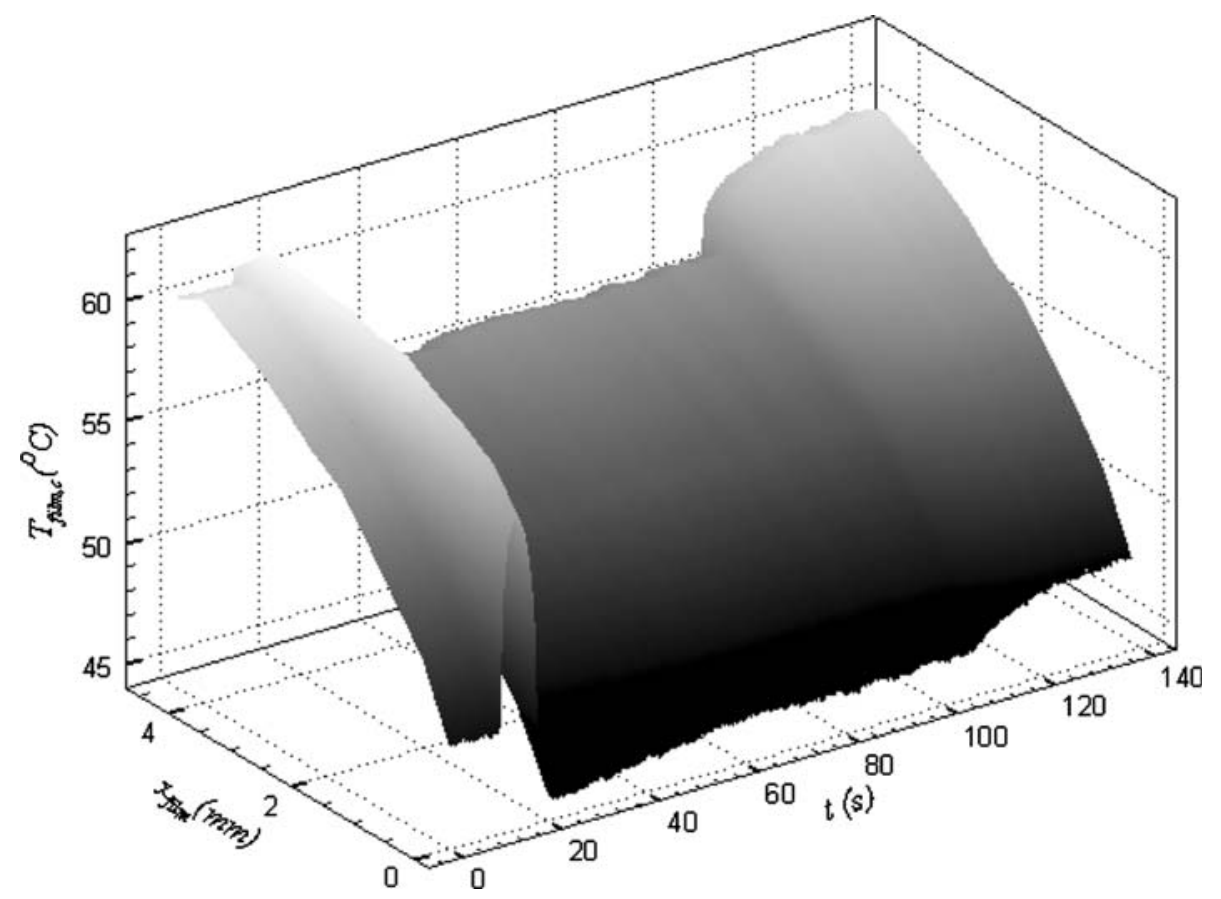

Fig. 10 Variations of pressure drop, fluid inlet and outlet temperatures, heating surface temperatures with and without triggering seed bubbles for $G=377.9 \mathrm{~kg} /\left(\mathrm{m}^{2} \mathrm{~s}\right)$, $q=316.4 \mathrm{~kW} / \mathrm{m}^{2}$, $B o=0.001634, f=1,000 \mathrm{~Hz}$ (mode 3 seed bubble triggered heat transfer)
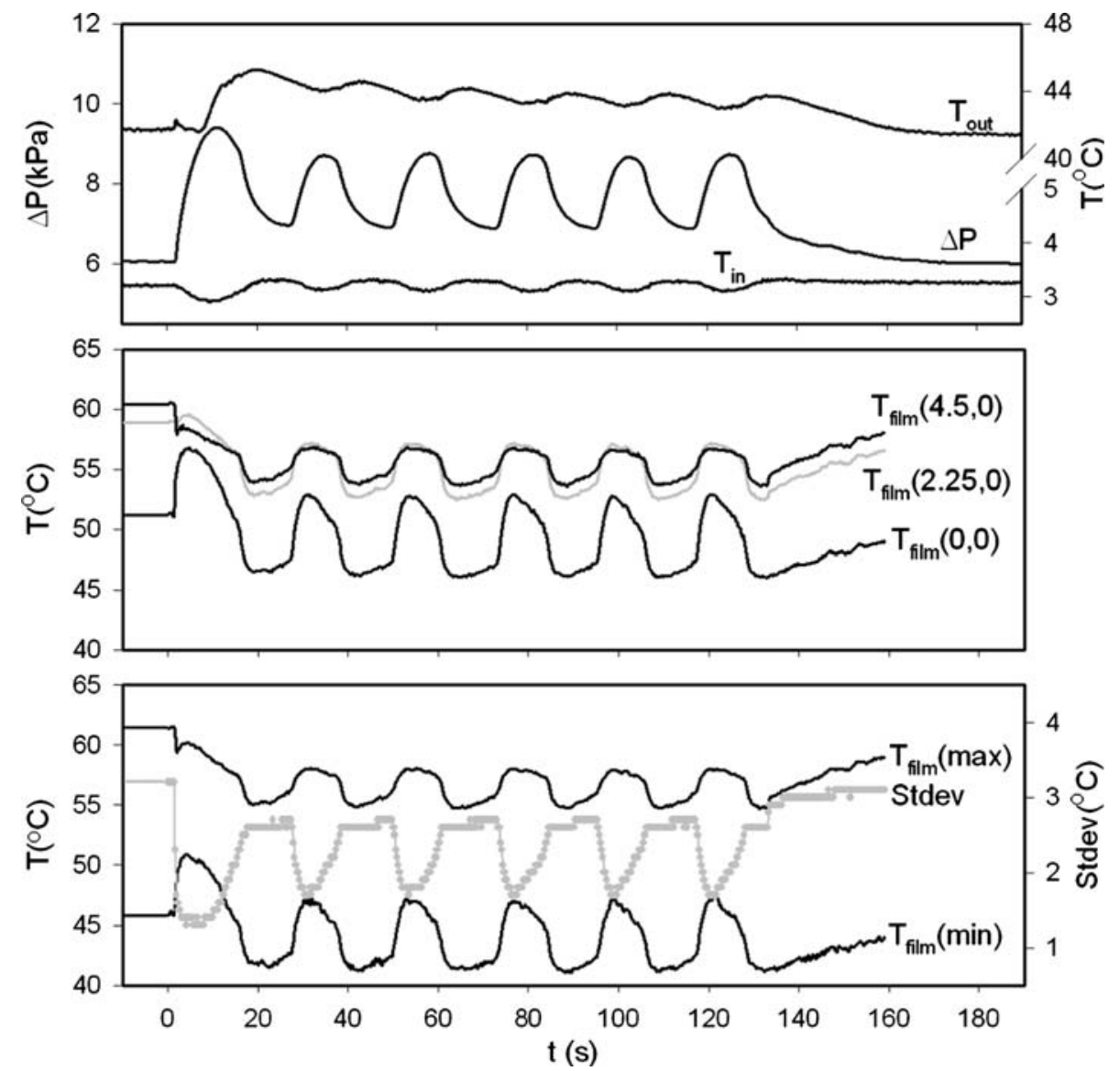

this mode have much smaller oscillation amplitudes of pressure drops and temperatures, compared with those reported in the literature such as $\mathrm{Wu}$ and Cheng (2003).
The three-dimensional distributions of temperatures at the centerline of heating surface versus time are shown in Fig. 11b. 
Fig. 11 a Alternative bubble and elongated bubble flow with apparent oscillation amplitude and long period for mode 3 seed bubble triggered heat transfer, b temperature oscillations with apparent amplitude and long period for mode 3 seed bubble triggered heat transfer

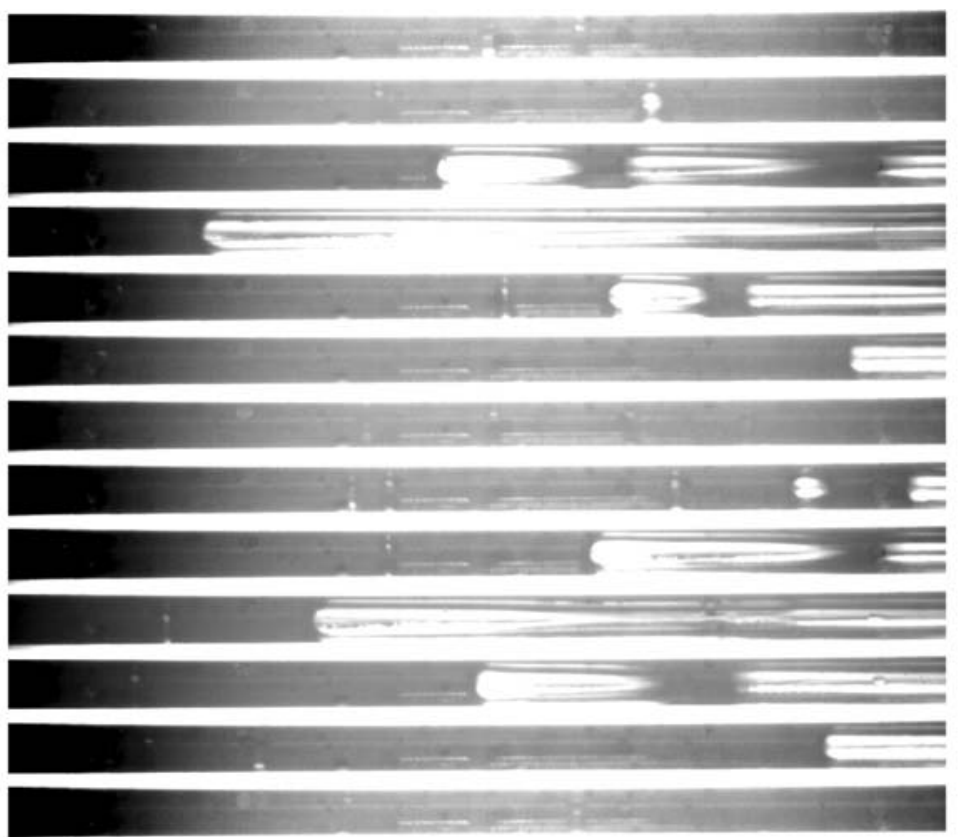

18.0

27.5

28.0

31.0

33.0

35.0

40.0

50.0

52.0

53.0

55.0

58.0

(a) $\mathrm{Ch} \# 1$

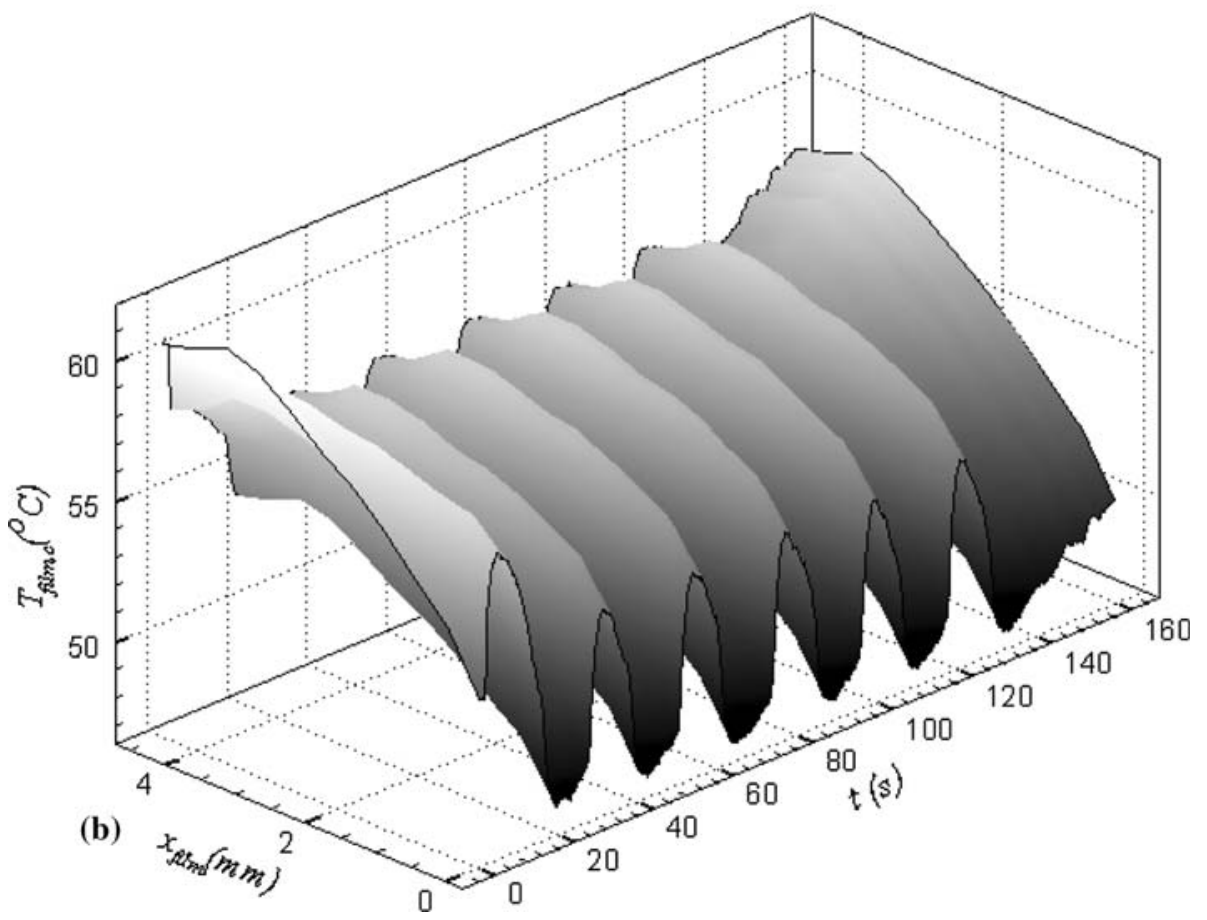

The present paper deals with low boiling numbers so that bubble nucleation is not initiated. Seed bubbles successfully trigger boiling heat transfer, involving stable and unstable heat transfer depending on the operation range of boiling numbers. In Xu et al. (2009) we reported the seed bubble stabilized flow and heat transfer under higher boiling numbers, under which oscillating boiling heat transfer is self-sustained in microchannels without seed bubbles assisted. Low frequency $(f<50 \mathrm{~Hz})$ seed bubbles mitigate oscillating boiling heat transfer. High frequency $(f>50 \mathrm{~Hz})$ seed bubbles completely stabilize flow and heat transfer.

\subsubsection{Mode 4 seed bubble triggered heat transfer}

The seed bubble triggered heat transfer of this mode takes place at higher boiling numbers but the system still sustains the single-phase superheated liquid flow without seed 
Fig. 12 Variations of pressure drop, heating surface temperatures without and with triggering seed bubbles for $G=377.9 \mathrm{~kg} /\left(\mathrm{m}^{2} \mathrm{~s}\right)$, $q=397.5 \mathrm{~kW} / \mathrm{m}^{2}$, Bo $=0.002048, f=2,000 \mathrm{~Hz}$ (mode 4 seed bubble triggered heat transfer)
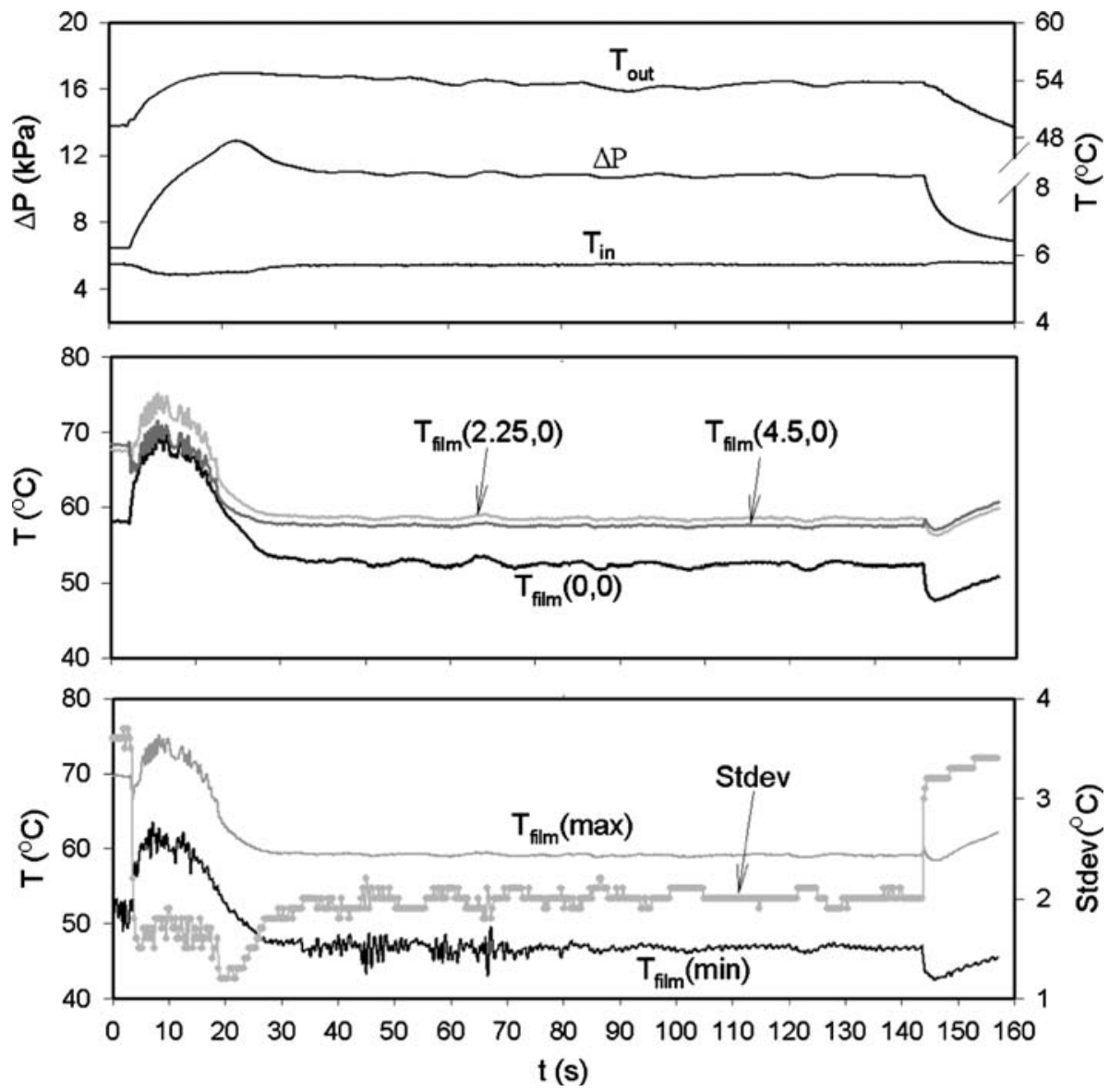

bubbles assisted. Pulse voltage signal frequencies can be low or high (see Fig. 3). An example run was given in Figs. 12 and 13 with $G=377.9 \mathrm{~kg} /\left(\mathrm{m}^{2} \mathrm{~s}\right), q=397.5 \mathrm{~kW} /$ $\mathrm{m}^{2}, B \mathrm{o}=0.002048$ and $f=2,000 \mathrm{~Hz}$. This is a very stable heat transfer mode, similar to that of mode 2 (see Figs. 7, 8, 9), except that growth of seed bubbles forms elongated bubbles in microchannels.

Because the boiling number is relative high, outlet fluid temperature reaches $54^{\circ} \mathrm{C}$, which approaches the saturation temperature of $56.3^{\circ} \mathrm{C}$ at atmospheric pressure assisted by seed bubbles. The initial maximum wall superheat (i.e., $\Delta T_{\text {sup, max }}=T_{\text {film,max }}-T_{\text {sat }}$ ) reached $14^{\circ} \mathrm{C}$ before triggering seed bubbles. However, heating surface temperatures are decreased by about $10^{\circ} \mathrm{C}$ after triggering seed bubbles. A short transition period is involved just after triggering seed bubbles (see Fig. 12). Flow patterns in the five microchannels are similar to those shown in Fig. 13a at any time. In Fig. 13a spheric seed bubble train exists in the microchannel upstream $(x<5-5.5 \mathrm{~mm})$ and elongated bubbles exist in the microchannel downstream $(x>5.5 \mathrm{~mm})$. Coalescence of elongated bubbles was observed. Flow pattern evolution in the timescale of milliseconds sustains a quasi-stable transition boundary from spheric bubble to elongated bubble in a narrow range within $x=5-5.5 \mathrm{~mm}$. The fast phase interface change can not cause oscillations of pressure drops and heating surface temperatures. Injection more seed bubbles in time sequence increases energy release from superheated liquid to vapor. Thus, thermal equilibrium of vapor and liquid phases could be approached. Heating surface temperatures are significantly decreased seeing in Fig. 13b, indicating great heat transfer enhancement.

Many papers (Kandlikar et al. 1997, Kandlikar 2006) indicated that boiling heat transfer should be initiated at high and positive liquid superheats in microchannels, inferring that boiling heat transfer in microchannels may not be subcooled boiling. The subcooled inlet liquid temperature has nothing to do with saturated or subcooled boiling in microchannels. The subcooled outlet fluid temperature is caused by the condensation heat transfer through the surface of the connection capillary tube at the silicon chip exit, and can not indicate subcooled boiling heat transfer in microchannels.

\subsection{Heat transfer enhancement by seed bubbles}

One may concern the degree of heat transfer enhancement by seed bubbles. We gave three runs in Fig. 14 with boiling numbers of $1.514 \times 10^{-3}, 1.801 \times 10^{-3}$, and $2.048 \times 10^{-3}$ 
Fig. 13 a Seed bubble growth and elongated bubble evolution for mode 4 seed bubble triggered heat transfer, $\mathbf{b}$ stable decreased heating surface temperatures measured by the IR imaging system without and with seed bubbles for mode 4 seed bubble triggered heat transfer
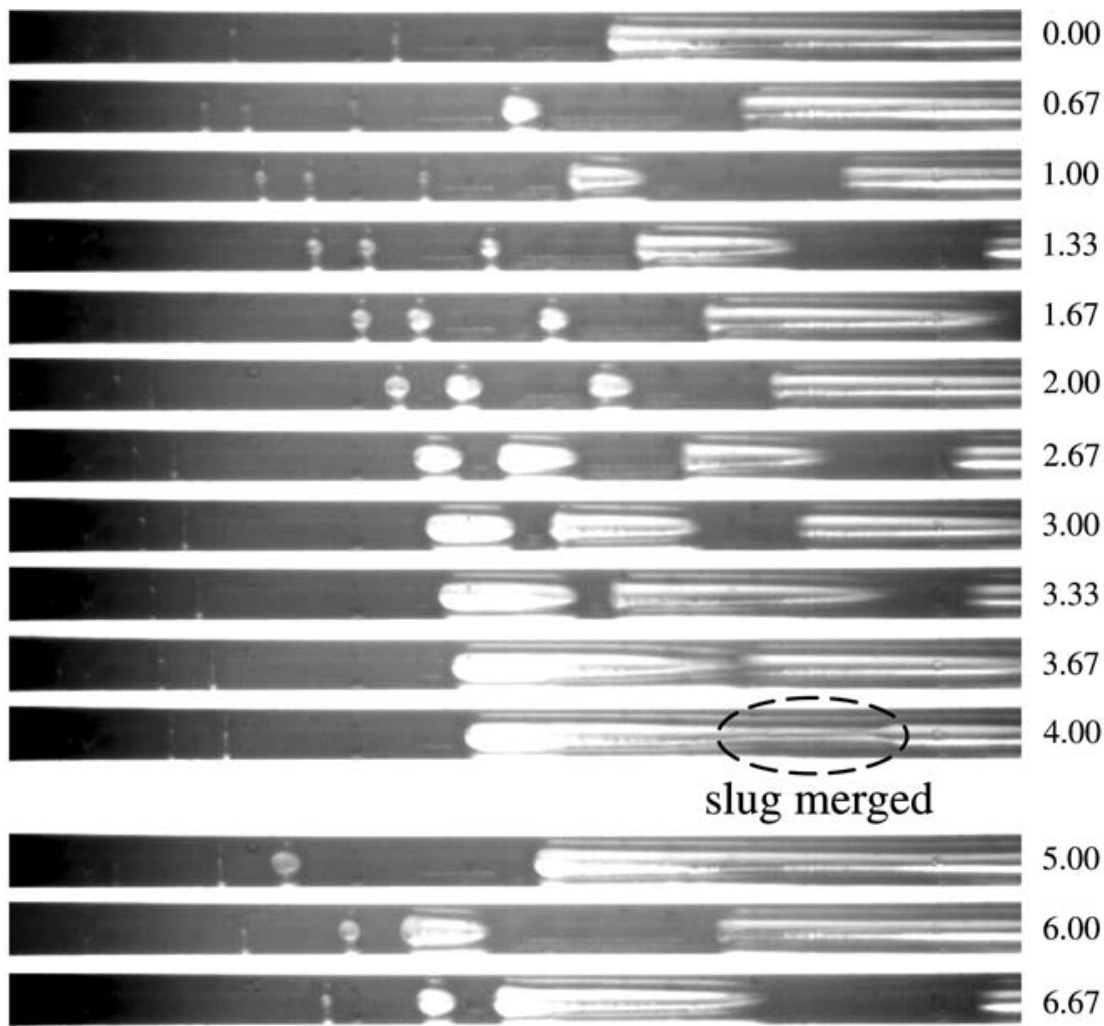

(a) $\mathrm{Ch} \# 1 \quad t(\mathrm{~ms})$

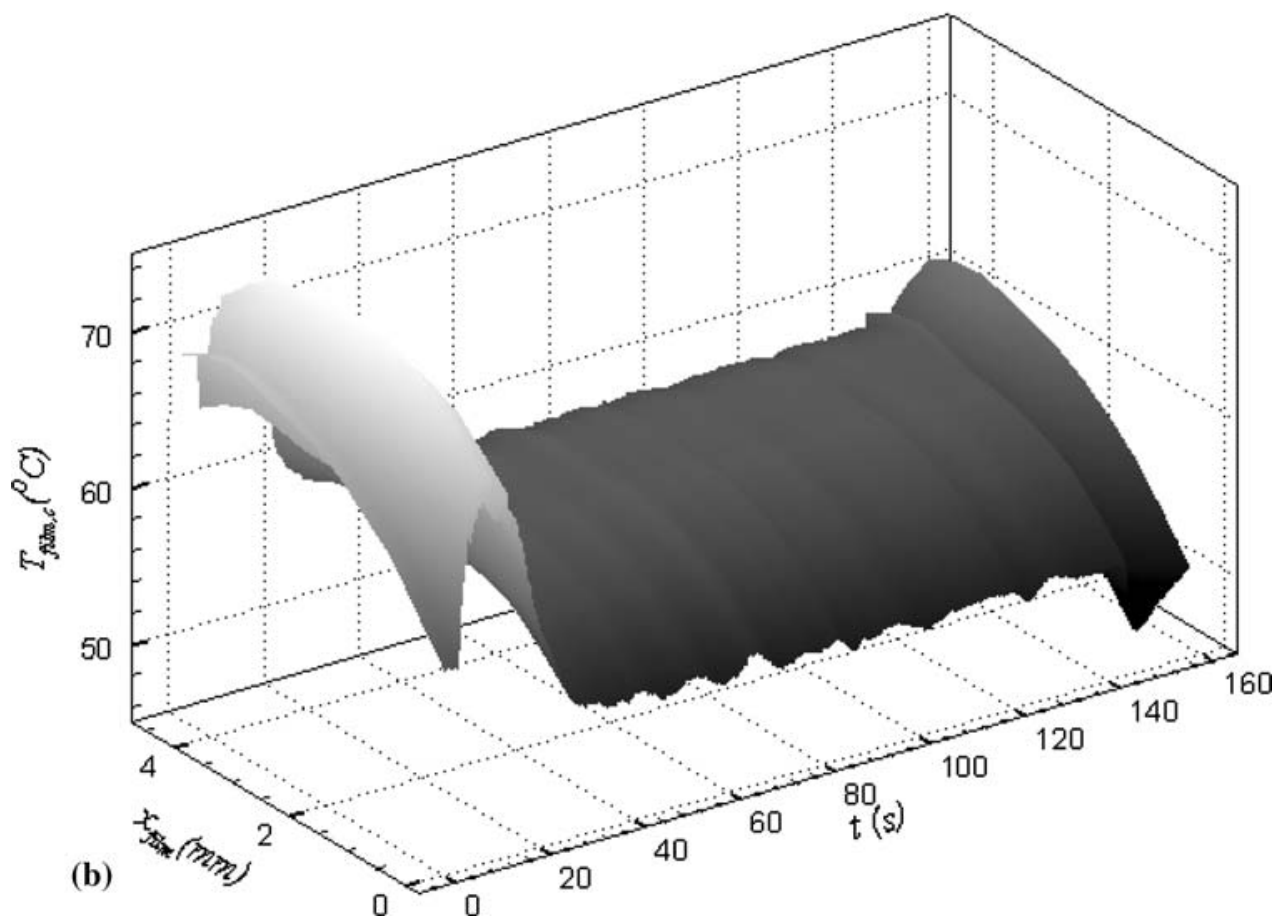

respectively. The saturation temperature of $56.3^{\circ} \mathrm{C}$ at atmospheric pressure was marked in each subfigure. Seed bubbles decrease heating surface temperatures for all the three runs shown. Seed bubble frequency is an important parameter to influence the degree of heat transfer enhancement. The higher the seed bubble frequency, the lower heating surface temperatures are. However, further heat transfer enhancement is not possible if the seed bubble 
frequency is larger than a couple of thousand Hertz. Thus, $f=1,000-2,000 \mathrm{~Hz}$ is called the saturation seed bubble frequency. Physically, when the seed bubble frequencies are continuously increased to a specific value, fully thermal equilibrium of vapor and liquid phases can be reached, under which temperature difference between liquid and vapor can be neglected, noting that the saturation seed bubble frequency is different for different microsystem design, heating power received and working fluids, which needs additional study.

Referring to Fig. 14a, temperatures at the centerline of heating surface are stable versus time without seed bubbles assisted and with seed bubble of $f=10,1,000$, and 2,000 Hz. Because $f=100 \mathrm{~Hz}$ belongs to the seed bubble triggered heat transfer of mode 3 , temperatures are given for both maximum and minimum values within the heat transfer instabilities. The two red curves represent the two boundaries for the temperature oscillations.

In Fig. 14b temperatures are oscillating versus time for all cases thus each seed bubble frequency coincidences with two boundary curves, except for $f=100 \mathrm{~Hz}$ and no seed bubble data. No matter for stable or unstable heat transfer, temperatures are lower than those without seed bubbles assisted.

Higher boiling number run was given in Fig. 14c for stable heat transfer. The seed bubble frequency is the key parameter to control heating surface temperatures. The degree of heat transfer enhancement by seed bubbles is large. For instance, maximum temperature superheat is $13^{\circ} \mathrm{C}$ without seed bubble assisted but it is $3.5^{\circ} \mathrm{C}$ by seed bubbles at $f=1,000 \mathrm{~Hz}$. For the low boiling number run shown in Fig. 14a, injection seed bubbles at $f=1,000$ $2,000 \mathrm{~Hz}$ maintains the maximum wall temperatures very close to the saturation temperature of $56.3^{\circ} \mathrm{C}$ at atmospheric pressure. Figure 14 gave a thermal management strategy: heating surface temperatures can be successfully controlled by changing seed bubble frequencies alone without change to the flow rate.

It is seen from Fig. 14 that temperatures achieve maximum values at about $3.5 \mathrm{~mm}$ and decrease at the end of heating area, noting that temperatures are only plotted in the heating area. The slightly negative temperature gradients at the end of heating area are due to the axial thermal conduction between the heating and un-heating areas. This is true even for no seed bubble cases. The slightly negative temperature gradients are similar to those reported in $\mathrm{Xu}$ et al. (2005).

The spatial-averaged heat transfer coefficient is calculated as

$\alpha=\frac{q_{\mathrm{sw}}}{T_{\mathrm{film}, \mathrm{a}}-T_{\mathrm{f}}}$

where $q_{\mathrm{sw}}$ is the heat transfer coefficient based on the two side wall surface of microchannels with the effective
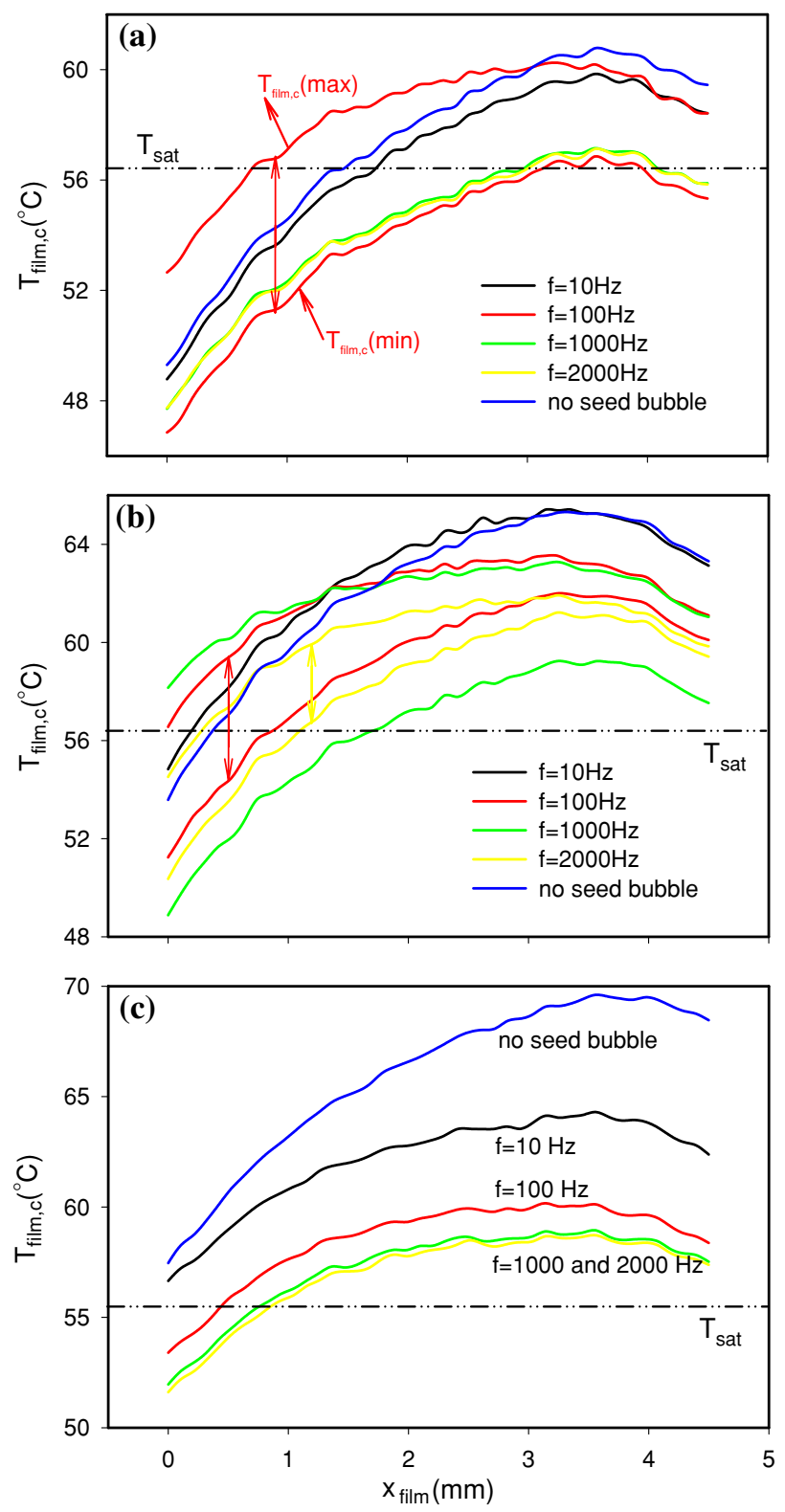

Fig. 14 Decreased heating surface temperatures depending on seed bubble frequencies: a $G=598.4 \mathrm{~kg} /\left(\mathrm{m}^{2} \mathrm{~s}\right), q=461.1 \mathrm{~kW} / \mathrm{m}^{2}$, $B$ o $=0.001514$. b $G=598.4 \mathrm{~kg} /\left(\mathrm{m}^{2} \mathrm{~s}\right), q=533.99 \mathrm{kw} / \mathrm{m}^{2}, B \mathrm{o}=$ 0.001801 . c $G=377.9 \mathrm{~kg} /\left(\mathrm{m}^{2} \mathrm{~s}\right), q=397.5 \mathrm{~kW} / \mathrm{m}^{2}, B o=0.002048$

heating length of $4,500 \mu \mathrm{m}, T_{\text {film }}$ is the average temperature on the main heater surface of $4,500 \mu \mathrm{m} \times 1,366 \mu \mathrm{m}, T_{\mathrm{f}}$ is the fluid temperature. It is noted that $\alpha$ may be changed with respect to time for oscillating flow and heat transfer. Table 3 gave the heat transfer coefficients for the runs identical to those in Fig. 14. In such a table, only one heat transfer coefficient is given for stable heat transfer, but heat transfer coefficients are given for both minimum and maximum values for oscillating heat transfer. For instance, ' 44.31 (56.21)' refers to the minimum value of $44.31 \mathrm{~kW} /$ $\left(\mathrm{m}^{2} \mathrm{~K}\right)$ and the maximum value of $56.21 \mathrm{~kW} /\left(\mathrm{m}^{2} \mathrm{~K}\right)$. It is 
Table 3 Heat transfer coefficients with and without seed bubbles

\begin{tabular}{|c|c|c|c|c|c|c|c|}
\hline \multirow[t]{2}{*}{$G\left[\mathrm{~kg} /\left(\mathrm{m}^{2} \mathrm{~s}\right)\right]$} & \multirow[t]{2}{*}{$q\left(\mathrm{~kW} / \mathrm{m}^{2}\right)$} & \multirow[t]{2}{*}{ Bo $\left(\times 10^{3}\right)$} & \multicolumn{5}{|l|}{$f(\mathrm{~Hz})$} \\
\hline & & & $\begin{array}{l}0 \\
\alpha[\mathrm{kW}\end{array}$ & $\begin{array}{r}10 \\
\mathrm{~K})]\end{array}$ & 100 & 1,000 & 2,000 \\
\hline \multirow[t]{2}{*}{598.4} & 461.10 & 1.514 & 61.89 & 78.15 & $70.04(79.05)$ & 102.47 & 106.41 \\
\hline & 533.99 & 1.801 & 35.56 & 39.46 & $44.31(56.21)$ & $45.90(108.98)$ & $57.01(112.3)$ \\
\hline 377.9 & 397.50 & 2.048 & 17.92 & 29.81 & 61.63 & 90.34 & 98.55 \\
\hline
\end{tabular}

seen from Table 3 that heat transfer is enhanced significantly by seed bubbles. For instance, for the case of $G=377.9 \mathrm{~kg} /\left(\mathrm{m}^{2} \mathrm{~s}\right), q=397.5 \mathrm{~kW} / \mathrm{m}^{2}$ and $B o=0.002048$, heat transfer coefficient is $17.92 \mathrm{~kW} /\left(\mathrm{m}^{2} \mathrm{~K}\right)$ for the no seed bubble data, but it is increased to $98.55 \mathrm{~kW} /\left(\mathrm{m}^{2} \mathrm{~K}\right)$ with seed bubbles assisted at $f=2,000 \mathrm{~Hz}$.

\section{Conclusions}

In microsystems, smooth channel surface causes high boiling incipience temperatures. We study using seed bubbles to trigger boiling incipience and control thermal non-equilibrium of vapor and liquid phases in microchannels. Seed bubbles are created on microheater surfaces driven by pulse voltage signals. Their size can be several to ten microns. The electrical energy consumed by microheaters is very small compared to the heat load in the main heater. With the data range reported here, the small wall superheats of less than $15^{\circ} \mathrm{C}$ ensure no bubble nucleation in microchannels without seed bubbles assisted. The seed bubble triggered heat transfer consists of four modes, in which modes 1 and 2 involve stable heat transfer, referring to either the alternating liquid and elongated bubble flow with the switch frequency identical to that of pulse voltage signal for mode 1 , or the seed bubble train flow in microchannels for mode 2. Mode 3 behaves flow instabilities with apparent oscillating amplitudes and long periods of pressure drops and heating surface temperatures. Alternating bubble flow and elongated bubble flow appear in microchannels, with low switch frequency that is different from that of the pulse voltage signal. Mode 4 takes place at high boiling numbers and behaves stable pressure drops and heating surface temperatures but self boiling does not happen. Quasi-stable seed bubbles and elongated bubbles coexist in microchannels at any time. Evolution of flow patterns in millisecond timescale involves a quasi-stable interface boundary from seed bubble to elongated bubble oscillating within a very narrow distance range that is less than a half millimeter.

Seed bubbles control the thermal non-equilibrium of vapor and liquid phases in microchannels. The non-equilibrium refers to the temperature difference between liquid and vapor phases, which is different from wall superheat defined as wall temperature subtracting fluid temperature. The higher the seed bubble frequency, the more decreased thermal non-equilibrium between two phases and heating surface temperatures are. But seed bubble frequency can approach a saturation value, at which the thermal equilibrium of two phases is approached. In this study, the saturation seed bubble frequency is about a couple of thousand Hertz.

Acknowledgments This work is supported by the National Natural Science Foundation of China with the contract number of 50825603.

\section{References}

Chang KH, Pan C (2007) Two-phase flow instability for boiling in a microchannel heat sink. Int J Heat Mass Transf 50:2078-2088

Garrity PT, Klausner JF, Mei RW (2007) A flow boiling microchannel evaporator plate for fuel cell thermal management. Heat Transf Eng 28:877-884

Hetsroni G, Mosyak A, Pogrebnyak E, Segal Z (2005) Explosive boiling of water in parallel micro-channels. Int $\mathrm{J}$ Multiphase Flow 31(4):371-392

Huh C, Kim J, Kim MH (2007) Flow pattern transition instability during flow boiling in a single microchannel. Int $\mathrm{J}$ Heat Mass Transf 50:1049-1060

Kandlikar SG (2002) Fundamental issues related to flow boiling in minichannels and microchannels. Exp Thermal Fluid Sci 26:389-407

Kandlikar SG (2006) Nucleation characteristics and stability considerations during flow boiling in microchannels. Exp Thermal Fluid Sci 30:441-447

Kandlikar SG, Mizo VR, Cartwright MD, Ikenze E (1997) Bubble nucleation and growth characteristics in subcooled flow boiling of water, HTD-vol 342. In: ASME Proceedings of the 32nd national heat transfer conference, vol 4, pp 11-18

Lin L (1998) Microscale thermal bubble formation, thermophysical phenomenon and applications. Microscale Thermophys Eng 2:71-85

Liu D, Lee PS, Garimella SV (2005) Prediction of the onset of nucleate boiling in microchannel flow. Int $\mathrm{J}$ Heat Mass Transf 48:5134-5149

Maurya DK, Das S, Lahiri SK (2005) Silicon MEMS vaporizing liquid microthruster with internal microheater. J Micromech Microeng 15:966-970

Sato T, Koizumi Y, Ohtake H (2008) Experimental study on fundamental phenomena of boiling using heat transfer surfaces with well-defined cavities created by MEMS (effect of spacing between cavities). J Heat Transf ASME 130(8) (article Number 084501) 
Thome JR (2004) Boiling in microchannels, a review of experiment and theory. Int $\mathbf{J}$ Heat Fluid Flow 25:128-139

Thome JR, Dupont V (2007) Heat transfer assembly, European Patent EP 1779052 B1, 28 November 2007

Wu HY, Cheng P (2003) Visualization and measurement of periodic boiling in microchannels. Int J Heat Mass Transf 46(14):26032614

Xu JL, Gan YH, Zhang DC, Li XH (2005) Microscale heat transfer enhancement using thermal boundary layer concept. Int $\mathrm{J}$ Heat Mass Transf 48:1662-1674
Xu JL, Liu GH, Zhang W, Li Q, Wang B (2009) Seed bubbles stabilize flow and heat transfer in parallel microchannels. Int $\mathrm{J}$ Multiphase Flow (in press)

Yaws CL (1999) Chemical Properties Handbook. McGraw-Hill, New York

Yu CK, Lu DC, Cheng TC (2006) Pool boiling heat transfer on artificial micro-cavity surfaces in dielectric fluid FC-72. J Micromech Microeng 16:2092-2099 